Illinois State University

ISU ReD: Research and eData

Theses and Dissertations

4-28-2016

\title{
Beyond The Millennium Development Goals: An Evaluation Of The War On HIV/AIDS In Kenya
}

Robert G. Nyaga

Illinois State University, robertnyaga@gmail.com

Follow this and additional works at: https://ir.library.illinoisstate.edu/etd

Part of the Communication Commons, and the Public Health Education and Promotion Commons

\section{Recommended Citation}

Nyaga, Robert G., "Beyond The Millennium Development Goals: An Evaluation Of The War On HIV/AIDS In Kenya" (2016). Theses and Dissertations. 589.

https://ir.library.illinoisstate.edu/etd/589

This Thesis is brought to you for free and open access by ISU ReD: Research and eData. It has been accepted for inclusion in Theses and Dissertations by an authorized administrator of ISU ReD: Research and eData. For more information, please contact ISUReD@ilstu.edu. 
BEYOND THE MILLENNIUM DEVELOPMENT GOALS: AN EVALUATION OF THE WAR ON HIV/AIDS IN KENYA

\author{
Robert G. Nyaga
}

\title{
119 Pages
}

HIV/AIDS remains a threat to Kenya and other developing nations. This thesis aimed at assessing the HIV/AIDS situation in Kenya by examining the knowledge of Kenyans towards infection and spread HIV/AIDS, attitudes towards people living with HIV/AIDS, involvement of community opinion leaders in the HIV/AIDS campaigns, sharing of HIV/AIDS information, and government efforts to control HIV/AIDS. A sample of Kenyans ( $N=103)$ was surveyed and asked to respond to several scales assessing each of the above items. Quantitative and qualitative methods reveal the knowledge and attitudes portrayed by Kenyans and show that although much has been achieved, there is need for multi-strategies to help curb the spread of HIV/AIDS. The results revealed some knowledge gaps concerning the infection and spread of HIV/AIDS and unfavorable attitudes towards people living with the pandemic. Specific theoretical implications, limitations, strengths, and suggestions for future research are discussed in detail. 
KEYWORDS: HIV/AIDS, MDGs, Culture, Entertainment Education, DOI, Knowledge, Attitude, Interventions. 
BEYOND THE MILLENNIUM DEVELOPMENT GOALS: AN EVALUATION OF

THE WAR ON HIV/AIDS IN KENYA

ROBERT G. NYAGA

A Thesis Submitted in Partial

Fulfillment of the Requirements

for the Degree of

MASTER OF ARTS

School of Communication

ILLINOIS STATE UNIVERSITY

2016 
(C) 2016 Robert G. Nyaga 
BEYOND THE MILLENNIUM DEVELOPMENT GOALS: AN EVALUATION OF THE WAR ON HIV/AIDS IN KENYA

ROBERT G. NYAGA

COMMITTEE MEMBERS:

John R. Baldwin, Chair

Lance Lippert

Kevin R. Meyer 


\section{ACKNOWLEDGMENTS}

All glory for this work is to the Almighty God, without whom not even a page of this study would have been written. Indeed, his unfailing grace and love were abundant throughout the research process. I would also like to thank my committee members; Dr. John Baldwin, Dr. Kevin Meyer, and Dr. Lance Lippert, for guidance and help during the writing process. I am particularly grateful to the chair of the committee, Dr. John Baldwin, who always advised me throughout the research process of this thesis and for always sparing time from his busy schedule to help me whenever I needed his assistance. It has been an interesting journey working with you, Dr. Baldwin, and I am grateful for always encouraging me to write better and believing in my abilities.

Dr. Meyer and Dr. Lippert, you have always been available whenever I needed your help, either with running data, reading materials or just advice in the course of conducting this study. You made me believe in my abilities and know that no matter how difficult a situation looks, with determination and help from others, the brave always reach their destination. I am humbled by your humility, kindness, and inspiration.

Thanks to my family in Kenya, for the immeasurable love you have offered me throughout my academic life. You have always offered me shoulders to lean on whenever I need support. Those calls were really helpful, especially during the tough times when the journey seemed too long and unending. You people inspired me to dare to dream, and to believe that, so long as I remained focused, no mountain would be insurmountable. 
Though thousands of miles away, you forever remain in my thoughts and prayers. To my colleagues in graduate school, who I could always count on whenever I needed help, thank you. I am especially grateful to my supervisor, Nathan Carpenter, who has been like a brother to me, always willing to give me time to work on my class assignments and write this thesis.

How can I forget my friends in Kenya, who always called or sent me messages on Facebook and WhatsApp to check on my progress? You gave me a reason to believe that true friendship transcends geographic boundaries and no matter the physical barriers, true friends never leave, thank you so much, I am grateful.

I am grateful to all the participants who took part in this study. This study would not have been possible, without your input. You sacrificed your time and resources to help me with the survey. Although, you never met me, you took time to help me with this study; I am grateful.

Lastly, but not least, I am grateful to the School of Communication, Illinois State University, for the opportunity to study and hone my skills, under the guidance of passionate faculty. This is the place I called home for two years, and although my memory may fade with age, you will forever have a special place in my heart. All the experiences I have had in this place, whether sweet or bitter, will forever define my world. Thank you awesome people!

This thesis is dedicated to the memories of my late dad, Nyaga, and late grandparents who never lived to see me climb the academic ladder this far. Although gone when I was very young, I still hold dear the values you bequeathed to me. I will 
forever treasure the short time we enjoyed together and the seeds of greatness you planted in me. May your souls rest in eternal peace.

R. G.N. 


\section{CONTENTS}

Page

ACKNOWLEDGMENTS $\quad$ i

CONTENTS IV

TABLES vii

CHAPTER

I. BACKGROUND OF THE STUDY 1

Statement of the Problem 2

Purpose of the Study 3

Significance of the Study 3

Conclusion 4

II. LITERATURE REVIEW 5

Definition of Terms and HIV/AIDS Transmission 5

HIV/AIDS in Kenya $\quad 6$

Factors Contributing to the Spread of HIV/AIDS in Kenya 10

$\begin{array}{ll}\text { Cultural practices } & 10\end{array}$

Religion and spirituality $\quad 14$

Economic factors 15

Stigmatization of HIV/AIDS 16

Laws and policies $\quad 19$

Methods of Combating HIV/AIDS $\quad 21$

ABC method 21

Male circumcision $\quad 23$

Education $\quad 24$

Community engagement 26 
Fear Appeals $\quad 29$

Entertainment Education in HIV/AIDS Messages 31

Elements of entertainment education campaigns 32

The growth of entertainment education 33

Importance of entertainment education in health campaigns 34

Effects of HIV/AIDS on Development 36

Millennium Development Goals 39

Theoretical Framework 41

Relative Advantage $\quad 46$

Compatibility $\quad 47$

Complexity 47

Trialability 47

Observability 47

Current Study, Research Questions, and Hypotheses 47

Conclusion $\quad 51$

III. METHODS 52

Participants $\quad 52$

Data Collection $\quad 53$

Measures $\quad 54$

$\begin{array}{ll}\text { Procedures } & 57\end{array}$

Data Analysis $\quad 58$

$\begin{array}{ll}\text { Conclusion } & 60\end{array}$

$\begin{array}{ll}\text { IV. RESULTS } & 61\end{array}$

HIV/AIDS Knowledge $\quad 61$

Perceptions of the Efficacy of Health Communication Interventions 64

Attitudes Toward People Living with HIV/AIDS 65

Quantitative Data $\quad 65$

Qualitative Data 67

Perceptions of Media Information on HIV/AIDS 69

Perceptions of Opinion Leaders $\quad 70$

Perceptions of Government’s Role in HIV/AIDS Campaigns 72 
Free Medical Services Provided by the Government

Adequate Resource Allocation

Inadequate Resources

Corruption

Diversion of Attention to Other Diseases

Frequent Strikes by Health Workers

Conclusion

V. DISCUSSION

Summary of Findings

Quantitative Analysis

Qualitative Analysis

Implications

Theoretical Implications 


\section{TABLES}

Table Page

1. HIV/AIDS Knowledge Portrayed by Kenyans 63

2. HIV/AIDS Communication Interventions 65

3. The Effects of Involving Opinion Leaders in HIV/AIDS Campaigns 71

4. Sharing of HIV/AIDS Information 72 


\section{CHAPTER I}

\section{BACKGROUND OF THE STUDY}

Approximately 25 million people worldwide have died from Acquired Immune Deficiency Syndrome (AIDS) and another 40 million live with the disease today (Qiao, 2011). Sub-Sahara Africa is the hardest hit of all the regions of the world (Muturi \& Mwangi, 2011; Oluga, Kiragu, Mohamed, \& Walli, 2010). Oluga et al. (2010) argue that whereas only $10 \%$ of the world population resides in East Africa, the region is home to 70\% of the people living with Human Immunodeficiency Virus (HIV) and AIDS

globally. Further, the region has an HIV/AIDS prevalence rate of 12-25\% and an average duration from HIV infection to death of about nine years, the lifetime chances of dying from AIDS is around 40\% in East Africa (Qiao, 2011). According to the recent figures released by the National AIDS and Sexually Transmitted Infections Control Program (NASCOP) in 2014, the HIV/AIDS prevalence in Kenya remains high, with an adult prevalence rate of $7.0 \%$ and with more women (7.6\%) than men (5.6\%) being victims of the pandemic. It is reasonable to infer that the control of HIV/AIDS has failed, because the communication of HIV/AIDS interventions have been unsuccessful in influencing behavior change, possibly because they are designed without careful consideration of the socio-cultural factors in the target communities.

In Sub-Saharan Africa, HIV/AIDS is mainly transmitted through heterosexual intercourse (Ayikukwei et al., 2008; Bekele \& Eggermont, 2014). Although the 
governments and development partners in these countries have used immense resources to mitigate HIV/AIDS, the pandemic still remains unabated. In Kenya, for instance, it is surprising that so many people continue to be infected with HIV even though condoms are distributed freely by the government in public places such as institutions of higher learning, pubs, hospitals, and public offices. The Kenyan government has also invested heavily in HIV/AIDS campaigns to sensitize the public on the pandemic, funded free voluntary counselling and testing centers (VCTs), and provided free antiretroviral drugs for those already infected. The high rate of new infections, therefore, not only merits concern but, also, requires critical investigation.

\section{Statement of the Problem}

In 2000, the global community came up with a commitment that came to be known as the millennium development goals (MDGs) (Dodd \& Cassels, 2006). The aim of the MDGs was to invent ways of boosting human development in developing countries. The world leaders gave themselves a time frame of 15 years to achieve the goals (Bernardi \& Chiara, 2011). One of the eight MDGs deals with control of HIV/AIDS. Last year, 2015, marked the deadline for the achievement of MDGs, but HIV/AIDS pandemic still remains out of control and new infections are still on the rise even after the deadline.

HIV-prevalence in Kenya is high in the age group between 15-64 years (Muturi \& Mwangi, 2011; Nesidai, Ng’ang’a, Mwangi, \& Wanzala, 2011). This is a worrying trend because this age group represents the labor force and future of the nation. Thus, HIV/AIDS poses social, political, and economic challenges to the future of the country. Nesidai et al. (2011) observed that the success of HIV/AIDS prevention programs lies in 
mass education and public awareness. However, although the Kenyan government and other development partners have spent millions of dollars educating the masses about the HIV/AIDS risk, these programs have largely not been successful; in that they have failed to prevent the spread of HIV/AIDS. Although many milestones in the control of HIV/AIDS have been achieved under MDGs, the lapse of the MDGs timeframe without effective mitigation of the disease warrants an investigation into the progress made so far in the control of HIV/AIDS.

\section{Purpose of the Study}

This study concentrates on germane studies concerning HIV/AIDS, which form the bedrock of this study. This thesis examines the perceptions toward the efficacy of HIV/AIDS interventions used so far in Kenya, factors contributing to the spread of HIV/AIDS, attitudes towards HIV-positive people, HIV/AIDS knowledge portrayed by Kenyans, and perceptions on credibility of various sources of information on HIV/AIDS. The study also aims to establish how the momentum on war on HIV/AIDS in Kenya can be sustained past the 2015 MDGs’ deadline.

\section{Significance of the Study}

Sub-Saharan Africa remains the leading region in the entire world in HIV/AIDSrelated infections and mortality rate (Muturi \& Mwangi, 2011; Oluga, Kiragu, Mohamed, \& Walli, 2010). The HIV/AIDS pandemic impacts all sectors of the economy and, therefore, greatly impedes development in the Sub-Saharan countries. The majority of those infected in Kenya are in their prime age and this has a negative impact on development. Whereas the ultimate control of HIV/AIDS was set as one of the MDGs, the rate of new infections remains high at 100,000 new infections per year in Kenya 
(National AIDS Control Council of Kenya \& NASCOP, 2014). This study is, therefore, important in the evaluation of the HIV/AIDS pandemic in Kenya, especially in establishing the knowledge and attitudes of Kenyans toward various aspects of HIV/AIDS such as infection; safe sex, and attitudes toward people living with HIV/AIDS.

\section{Conclusion}

This chapter briefly explains the importance of this study and reasons for its setting in Kenya. Whereas several strides have been made in the control of HIV/AIDS in Kenya, the high rate of infection indicates that more work needs to be done to curb the current trend of HIV/AIDS in the country. Therefore, it is important to examine the factors that continue to impede the control of the disease, as well as suggest new strategies to complement the existing ones based on the findings. The next chapter looks at the state of HIV/AIDS in Kenya, the factors contributing to the spread of the disease, methods of controlling HIV/AIDS, MDGs, an evaluation of the existing AIDS campaigns in Kenya, and the effects of HIV/AIDS. The succeeding chapter also explains the theoretical framework of the study. 


\section{CHAPTER II}

\section{LITERATURE REVIEW}

The HIV/AIDS pandemic is a global concern with serious political, economic, and social implications. Unlike other diseases that have ravaged humanity throughout history such as polio, measles, and leprosy, but were ultimately controlled, HIV/AIDS has defied all mitigation efforts. This chapter, therefore, reviews pertinent past literature on HIV/AIDS in Kenya, especially the factors that contribute to the spread of the disease, HIV/AIDS interventions, effects of HIV/AIDS on development, and the MDGs. The literature also borrows from other HIV/AIDS studies from other countries.

\section{Definition of Terms and HIV/AIDS Transmission}

This study assesses knowledge and attitudes of Kenyans to a variety of HIV/AIDS aspects such as infection, control, and stigmatization of the people living with HIV/AIDS. According to Singhal and Rogers (2003), knowledge refers to a person’s range of information on HIV/AIDS, while attitude refers to a person's opinion about HIV/AIDS. On the other hand, stigma is prejudice and discrimination against people living with HIV/AIDS and subjecting them to negative treatment (Singhal \& Rogers, 2003). HIV attacks the body’s natural defense systems against diseases by destroying one type of blood cells (CD4 cells), which help the body to fight off and destroy germs. CD4 cells belong to a group of blood cells called T- helper cells, which also help the body fight diseases (Shimbuli, Oyedokun, \& McNally, 2009). 
AIDS occurs when the immunity of an HIV positive person is weakened, thus predisposing him/her to opportunistic diseases. The HIV virus mutates at a high rate with one virus being able to mutate into 10 billion copies of itself in a day, making the virus difficult to control and at times resistant to drugs (Singhal \& Rogers, 2003).

\section{HIV/AIDS in Kenya}

In Kenya, HIV rates have dropped from approximately $10 \%$ in adults in the mid1990s to between 7- 8.5\% in 2007 (Van Buren, 2011). HIV-prevalence in Kenya is currently estimated at 7.0\% in the age group between 15-64 years (Muturi \& Mwangi, 2011; Nesidai et al., 2011; NASCOP, 2014). Despite the drop in the infection rate, HIV/AIDS remains a killer disease, especially for people in the prime age (Muturi \& Mwangi, 2011; Nesidai et al., 2011). Joint United Nations Program on HIV/AIDS (UNAIDS) in 2014 observed that East African nations offer the best indication that HIV/AIDS pandemic can be controlled, because of the significant progress that has been made in mitigating the spread of the pandemic. Van Buren (2011) contends that HIV/AIDS was first diagnosed in Kenya in 1984, but by then was not perceived as a serious threat because it was associated with homosexuality. However, between 1988 and 1991, the disease started being viewed as a potential threat to state development and social wellbeing.

Between 1992 and 1995, AIDS was declared a national crisis, but it was not until 1997 that the first national policy statement was formulated. HIV/AIDS was ultimately declared a national disaster in 1999 (Van Buren, 2011). Increased awareness of HIV/AIDS in the 1990s was mostly due to the realization by the government that the disease had negative social and economic effects. Most AIDS programs in Kenya are 
coordinated by the government and NGOs and mostly focus on sex education, community engagement, research, testing, counseling, and formulation of policies. Van Buren (2011) observed that most organizations in Kenya have shifted their AIDS campaign from the mere “AIDS kills” messages prevalent in the early years of the disease to more pertinent societal issues such as discrimination of AIDS patients and ways of engaging in safe-sex practices.

According to the 2014 figures on AIDS prevalence released by National AIDS Control Council of Kenya (NACC) and National AIDS and Sexually Transmitted Infection Control Program (NASCOP), Kenya ranks fourth in the world in terms of the prevalence of AIDS after India, Nigeria, and South Africa. The United States Agency for International Development (USAID), Kenya (2013) reports that the HIV/AIDS prevalence in the country stands at 1.6 million people, and 1.1 million children are orphans due to HIV/AIDS.

Urban centers have higher rates of infection than the rural areas. Lack of knowledge about the disease and deceptive beliefs among the youth, such as a misconception that engaging in repeated sex makes one immune to $\mathrm{HIV}$, are some of the factors contributing to the spread of the HIV/AIDS in Kenya (Van Buren, 2011). Van Buren contends that conflicting AIDS messages from the government, religious groups, and civil society in Kenya have created confusion on the adoption of safe-sex practices, as they tend to be contradictory and focus on different aspects of HIV/AIDS. Going forward, it is important for the stakeholders involved in drafting HIV/AIDS policies and campaigns to work in synergy so as to work towards achieving the same goals and 
disseminate messages that encourage behavior change, while at the same time, taking into account the religious and social sensitivities of the target audience.

Women are the most affected by the epidemic compared to men, with women's infection standing at 59\% and women in the age bracket of $15-24$ years twice likely to be infected as compared to their male counterparts (Sia, Onadja, Nandi, Foro, \& Brewer, 2013). Sia et al. argue that the discrepancy in infection between men and women could be because of the physiological and socio-economic factors that disadvantage women and make them more vulnerable to contract HIV/AIDS through sexual intercourse. This argument is also advanced by Singhal and Rogers (2003) who observed that women are more vulnerable to HIV infections and bear the brunt of stigma if infected, because they are least empowered to negotiate for safe-sex, and the patriarchal culture in many developing countries increases their dependence on men. Many of these young women in Kenya have been infected by men who are several years older and, therefore, more likely to be living with HIV due to their many years of sexual encounters in a HIV/AIDS-prone environment (USAID, 2013). One way of addressing the HIV/AIDS pandemic in Kenya, therefore, lies in emancipating women through economic and social empowerment to ensure they are not overly dependent on their male counterparts in making decisions that have impact on their health.

Increased global access to antiretroviral (ARV) drugs has enabled people living with HIV/AIDS to live productive and longer lives (Chang, Prytherch, Nesbitt, \& WilderSmith, 2013). In Kenya, ARVs are provided at no cost in all government funded health institutions. This has enabled people living with HIV/AIDS to continue contributing to the economy without their lives being cut short by the pandemic. However, the stigma 
associated with HIV/AIDS prevents many people from getting tested, thus many people do not know their HIV status, and do not, therefore, start using ARVs in time if infected.

Prevention and early diagnosis of HIV/AIDS remain the globally advocated methods of combating the disease (Muturi \& Mwangi, 2011). Although the government of Kenya offers free voluntary testing and counselling (VCT) in almost all public hospitals, it is unclear why the rates of infection still remain high, a year after the lapse of millennium development goals when HIV/AIDS ought to have been controlled. However, lack of information compounded with unprotected sex with multiple partners is a major reason for the high rate of infections in Kenya (Muturi \& Mwangi, 2011; Qiao, 2011). It is possible that the government and other development partners have not undertaken sufficient sensitization programs about testing and free medical services for those already infected. However, the prevailing economic challenges in Kenya could also push people to live care free lives and make risky sexual decisions that predispose them to HIV infection. Qiao (2011) argues that even when people are aware of the risks of contracting HIV, a sense of disillusionment with their future can prompt them to rationalize high risk and unsafe sexual practices. Thus, according to Qiao, if the future appears unattractive, because of the present economic stagnation and other social evils, individuals may take on careless habits and cease to fear death, thus end up engaging in risky sexual behaviors.

There is no single reason that can best explain the cause for the high rates of HIV/AIDS infections in Kenya as there are many factors that contribute to the spread of the pandemic. This study, therefore, just explores a few of those factors and gives an explanation how each one of them leads to HIV/AIDS infection. 


\section{Factors Contributing to the Spread of HIV/AIDS in Kenya}

Cultural practices. Culture is a learned dynamic cognitive frame constructed by a community, which influences how members of that community view the world (Lee, 2015). Culture offers a context through which health issues can be discussed and better understood (Airhihenbuwa \& Webster, 2012). Airhihenbuwa and Webster (2012) argue that most of the interventions used to fight HIV/AIDS in Africa are designed in developed western countries and are based on the education approaches in these countries, which assume uniform universal approaches to learning. Therefore, such interventions bear Western cultural aspects that, in most cases, are incompatible with African cultural practices. This position is also advanced by Tindall and VardemanWinter (2011), who observed that low success rate of interventions can be linked to the failure to consider culture when designing campaigns. Failure to consider the prevailing cultural beliefs of the target audience means that the designed health campaigns may contradict these beliefs, thus leading to either rejection by the audience or apathy, hindering the objectives of the campaigns.

Cultural empowerment can be an important tool of fighting HIV/AIDS, if the positive aspects of culture are incorporated in the campaigns while acknowledging the uniqueness of the cultural practices of the target audience and fitting scientific explanations into cultural contexts, so that they are understandable and acceptable to the local communities (Airhihenbuwa \& Webster, 2012; Singhal \& Rogers, 2003).

HIV/AIDS distribution in Kenya is not uniform among communities, as some regions are more affected than others due to some cultural practices that predispose people to HIV/AIDS and other sexually transmitted diseases (Ayikukwei et al., 2008). The success 
of the HIV/AIDS campaigns in Kenya, therefore, is dependent on the extent to which the health messages address the deceptive cultural practices that undermine the war on HIV/AIDS, and encourage people to eschew such practices and adopt safe-sex practices. Culture has been a major factor contributing to the spread of HIV/AIDS, because some cultural practices are difficult to address, as they are based on strong traditions and beliefs that are resistant to change (Ngula \& Miller, 2010; Oluga et al., 2010; Singhal \& Rogers, 2003). Singhal and Rogers (2003) argue that culture may hinder people from getting tested and treated for HIV/AIDS as a result of the stigma associated with the disease. Other factors such as male promiscuity and polygamy also contribute to the spread of HIV/AIDS. Female genital mutilation (FGM) has also been identified as one of the leading cause of AIDS in Africa (United Nations International Children’s Emergency Fund, 2013). In many instances, FGM involves sharing of surgical blades and is carried out in secrecy by quack traditional "medical practitioners," thus exposing the victims to the risk of not only infection, but also death in case of excessive bleeding.

Oluga et al. (2010) identified other cultural practices such as widow inheritance, sexual cleansing, sex with virgins to "cure” HIV/AIDS, and body tattooing with the same sharp objects as practices hindering the war on HIV/AIDS. Sexual cleansing involves a detailed procedure from the time of the death of a husband to the time the widow is "inherited" and reintegrated into the community (Ayikukwei et al., 2008). The practice is ostensibly carried out to cleanse the family of the bereaved from curses (chira) and spirits that might have caused the death of the widow's husband (Ayikukwei et al., 2008; Oluga et al., 2010; Singhal \& Rogers, 2003). Surprisingly, although these practices expose people to HIV/AIDS and infection by other sexually transmitted diseases, little care is 
taken to protect victims from danger. These cultural practices impede the war on HIV/AIDS because they expose people to new infections.

A good example of a community that practices sexual cleansing in Kenya is the Luo community (Ayikukwei et al., 2008). In this community, after the death of the husband, the widow is ostracized by the community and has to identify a cleanser in order to be reintegrated into the community. The cleansing process usually involves the widow having sex with a relative or brother of the deceased so as to cast out the spirit that caused the death of her late husband. The process also makes the widow an eligible wife once she is integrated back to the community. Ayikukwei et al. argue that sexual cleansing is practiced in many African countries such as Kenya, Uganda, Mali, Rwanda, Namibia, Burkina Faso, Sierra Leone, and Zambia and continues to be a contributing factor to the spread of HIV/AIDS in these countries.

Ayikukwei and colleagues (2008) contend that wife cleansing is based on deceptive cultural beliefs that it cannot lead to HIV/AIDS infection, the cleanser is not vulnerable to sexually transmitted diseases and so use of protection during cleansing is not allowed. These beliefs contradict scientific principles, because unprotected sexual intercourse is one of the major ways in which HIV/AIDS is spread. Use of condoms during sexual cleansing is forbidden for a couple of reasons, such as that men who use condoms make the ritual incomplete, the act has to be performed in the same way the late husband had sex with the widow, condoms are regarded as foreign inventions that contradict the society's traditions, and people do not like sensation caused by condoms (Ayikukwei et al., 2008). Women who refuse to be cleansed are ostracized by the 
community and cannot be accorded a decent burial in case they die without being cleansed.

Previous research has also identified misinformation and knowledge gaps regarding transmission and control of HIV/AIDS as other factors hampering the control of the HIV/AIDS menace. For example, in a study of older members of the Kikuyu community in Kenya, Muturi and Mwangi (2011) observed that most of them believe withdrawal and washing of genitals after sex can prevent them from HIV/AIDS infection. Oluga et al. (2010) observed that some communities view HIV/AIDS as a result of a curse and can be healed through herbal medicine or having sex with a virgin girl. Further, Oluga et al. also observed that men in some communities in Kenya view having multiple sexual partners as a sign of virility. This reinforces a similar observation by Singhal and Rogers (2003), who found that some Kenyan men view women as “trophies” and perceive having sex with many partners as a sign of masculinity. These deceptive beliefs can lead to transmission of HIV and other venereal diseases, and impede the momentum on the war on HIV/AIDS.

Oluga and colleagues (2010) found that some communities in Kenya and Tanzania prohibit pregnant women from eating certain meals such as eggs, fruits, vegetables, and fish because these foods are deemed harmful to the unborn babies. This hinders HIV/AIDS control using nutritional interventions, especially where the expectant mothers are HIV/AIDS positive, by depriving them of the important nutrients found in these foods. Other cultural aspects such as social norms that allow violence against women for example; spousal abuse and domestic violence, increase the risk of HIV/AIDS 
in women by making them unable to negotiate for safe sex with their male counterparts (Sia et al., 2013).

As seen from the examples above, culture hinders the war on HIV/AIDS in a number of ways. The health campaigns in Kenya should, therefore, aim to change the cultural practices that reverse the gains already made in the war on HIV/AIDS. However, it is important to take cognizance of the fact that cultural practices and attitudes take time to change; hence, persistence and patience are necessary. Closely related to culture are religion and spirituality, which are discussed in the succeeding paragraph.

Religion and spirituality. Religion and spirituality can be powerful tools in the war on HIV/AIDS, because they cut across age, gender, class, language, culture, geography, and occupation (Singhal \& Rogers, 2003). Spirituality and religion have both positive and negative effects in the war on HIV/AIDS. On the positive side, they are important in both the prevention and coping stages of HIV/AIDS. Singhal and Rogers (2003) argue that the incorporation of religion and spirituality in HIV/AIDS campaigns by Islamic and Buddhist leaders in Uganda and South East Asian Nations (ASEAN) respectively, led to the decrease of HIV/AIDS infection and provided coping strategies to the people living with the pandemic.

However, in Kenya, some safe-sex commercials are highly regulated due to the religious stands of various groups. In addition, the Pope, on a recent trip through Africa, banned the distribution of condoms in Catholic institutions (UNICEF, 2013). Muslim leaders have taken a similar stance. There is significant pressure from both Christian and Muslim religious leaders in regard to AIDS and preventive care education (Nesidai et al., 2011). Many religions still view HIV/AIDS as a punishment from God for indulgence in 
immoral sexual habits (Singhal \& Rogers, 2003). As a result, many health campaigns by the religious communities promote abstinence, ignoring the fact that many unmarried people actively engage in sex. Singhal and Rogers, for instance, observed that, in Trinidad and Tobago, abstinence health campaigns failed to address the problem of premarital sex among the youths, leading to several deaths. Continued emphasis on abstinence has hampered the progress of a variety of safe-sex campaigns (Nesidai et al., 2011; Singhal \& Rogers, 2003; UNICEF, 2013). This thesis argues that, although religion and spirituality are powerful tools in the war on HIV/AIDS, they have not been effective in to controlling HIV/AIDS in Kenya. Going forward, it is important for the health professionals involved in HIV/AIDS campaigns to reach out to the religious community, especially in the execution of the campaigns, because they can be helpful in transmitting the HIV/AIDS messages to their congregations.

Economic factors. The most obvious challenge to the AIDS pandemic is the lack of funding for medical facilities and research in developing countries (UNICEF, 2013). In Kenya, the single largest donor to HIV/AIDS programs is the US government, which has in recent years announced plans to reduce the amount of funds channeled towards these programs (NACC \& NASCOP, 2014). If the US government goes ahead with its threat to scale down the funding to HIV/AIDS projects, the burden of medication will be heavy for the people living with HIV/AIDS to bear and services such as VCT and free ARVs might be negatively affected. Such a situation will only reverse the gains made so far in the war on HIV/AIDS. Since, the majority of the people in Sub-Saharan Africa live below the poverty line and, as Qiao (2011) argues, may be suffering from disillusionment due to the 
prevailing current situation of poverty, such poor people may thus engage in risky sexual activities.

In Kenya, $81 \%$ of women compared to $64 \%$ of men have self-employment with meager earnings, and $47 \%$ of the 40 million population live below the poverty line (Gnauck et al., 2013). Also, 75\% of women in Kenya live in rural areas with agriculture as their only income generating activity and thus, lack adequate power in major national decision-making processes, such as representation in parliament and other positions of authority. Gnauck et al. also observed that the majority of those infected with HIV/AIDS live in rural parts of the country, with women having a higher infection rate than men due to marginalization and lack of power in negotiating for safe-sex. Singhal and Rogers (2003) attribute the high rate of HIV/AIDS infection among Kenyan women to the sexual exploitation of young women by affluent, middle-class men (sugar daddies) who lure them into sex with cash and promises of better lives.

The HIV/AIDS campaigns must, therefore, go beyond prevention of infection and aim at empowering vulnerable populations at risk of infection, such as women, as a way of sustaining the momentum on the gains already made in mitigating the pandemic. Empowering women will not only improve their capability to negotiate for safe sex with their male counterparts, but will also enable them to adopt practices that limit spread of HIV/AIDS, such as through mother-to-child at birth and stop cultural practices such as FGM that predispose them to HIV/AIDS infection.

Stigmatization of HIV/AIDS. One of the ways in which attitudes towards HIV/AIDS are displayed, is through stigma towards the infected people. Stigma involves stereotypical labeling of individuals and attributing undesirable characteristics to the 
labeled group (Yuh, Ellwanger, Potts, \& Ssenyonga, 2014). Throughout the world, antiAIDS stigma is a barrier to the humane treatment of infected individuals. HIV positive people are stereotyped as having behaved immorally and are punished accordingly (Singhal \& Rogers, 2003; Wilson, 2012). The rights of the HIV-positive people are also routinely violated by others. People infected with AIDS or who are HIV positive and their social groups have been stigmatized worldwide since the epidemic began (Taylor, 2013). In Nepal, for instance, Mahat, Scoloveno, and Ayres (2014) contend that HIV/AIDS is still stigmatized as a disease for sexually immoral people that is caused by bad karma.

Some of the consequences associated with HIV/AIDS-related stigma include isolation, fear of disclosing HIV status, and discrimination. Patients of some diseases such as HIV/AIDS and tuberculosis acquire certain identities that are difficult to dispel, and, once afflicted, the struggle to shed the "victim" identity (Taylor, 2013). Yuh et al. argue that HIV/AIDS-related stigma is socially constructed and is evident through negative attitudes and prejudice towards people living with HIV/AIDS and the groups they come from. In Africa, female sexual workers are blamed and held personally accountable for the spread of HIV/AIDS through risky sexual activities. The society does not, however, blame men who equally participate in irresponsible sexual acts, such as having multiple sex partners. This double standard not only exacerbates prejudice against an already vulnerable group, but also demeans women and encourages men to continue engaging in risky sexual acts that expose them to infection.

People with AIDS are blamed and viewed as responsible for the spread of the disease to others in the society. Stigma contributes to the spread of HIV/AIDS in that, on 
one hand, fear of disclosing serostatus due to fear of stigmatization separates one from social support that is important in coping with HIV/AIDS pandemic, while on the other hand, disclosing the serostatus leads to discrimination, divorce among married couples, and isolation from the community's social activities (Yuh et al., 2014). This dialectical tension, due to stigma, often contributes to the infection of the uninfected partner in a sexual relationship and hinders the war on HIV/AIDS.

Africa has high HIV/AIDS-related stigma with little commensurate structural interventions to address the pandemic. The stigma associated with HIV/AIDS is a barrier to prevention programs, inhibits effective testing and counseling, and in many cases interferes with effective treatment and care. Although several strides have been made to mitigate stigma of HIV/AIDS, diagnosed individuals and their families continue to suffer negative societal connotations associated with the disease (Yuh et al., 2014). People living with HIV/AIDS also experience psychological distress due to the HIV infection, reduction of CD4 count, and poor response to antiretroviral (ART) drugs (Seth et al., 2013). Seth et al. found that people with HIV routinely experience sexual and physical violence, dread disclosing their status for fear of losing friends, being gossiped by others, and mistreatment by family. Stigma often leads to depressive tendencies among people living with HIV/AIDS such as dependence on alcohol and substance abuse. Addressing stigma, therefore, encourages the society to offer social support to those already infected with HIV/AIDS and encourages an environment where open and honest discussions about the pandemic can occur.

Chicoine (2011) argues that HIV/AIDS may lead to discrimination at the workplace for those infected or perceived to be in the high risk infection age bracket, 
leading to reduction in their hiring, low wages, and inadequate investment to improve their skills. Stigma associated with HIV/AIDS in the long run may lead to social inequality. It is, therefore, evident that addressing stigma associated with HIV/AIDS boosts economic development, helps in eradication of poverty, and leads to social inclusion, where no one is discriminated on the basis of their health status. However, it is important to note that stigma is a complex problem that takes time to address, therefore, multi-strategies are required to deal with it, as well as encourage tolerance for people living with HIV/AIDS.

Laws and policies. Laws are important in ensuring holistic protection and care in situations where individuals are vulnerable to discrimination due to their gender, religion, age, or health status (Gruskin et al., 2013). Increased globalization has enabled people to travel to different places of the world thus influencing epidemiology. In the early years of the HIV pandemic, many countries imposed travel restrictions on HIV positive people as a way of securing their boundaries and preventing further costs related to the mitigation of the disease (Chang et al., 2013). Under these laws and policies, people are screened for HIV/AIDS before they can be allowed to travel to certain countries, and if found to be infected, they are denied entry to those countries or subjected to unwarranted harassment as a way of discouraging them from visiting such nations. Such restrictions perpetuate discrimination of people living with HIV/AIDS and make the pandemic look like an evil that should be punished. These acts impede the war on HIV/AIDS.

Many international organizations and health practitioners oppose these restrictions on grounds that they are impractical, promote stigma, and violate human rights (Chang et al., 2013). However, 45 out of 193 (23\%) WHO member states still restrict movement of 
people on HIV related grounds. The majority of these are in Western Mediterranean, Western Pacific, and Europe. The western Mediterranean has the highest number of countries (60\%) with restrictions (Chang et al., 2013). Those mostly targeted by the restrictions are non-nationals intending to stay in these countries for longer periods (e.g., expatriates and immigrants). Chang et al. (2013) argue that most of the countries that impose travel restrictions do so for various political reasons such as dependency on migrant labor, desire to preserve a positive public opinion from the voters, lack of national policies on HIV/AIDS, and to protect their cultures from external influences.

Kenya has relatively weak laws that protect HIV positive people and guide the war on HIV/AIDS. Absence of strong institutions, laws, and policies in the country contribute to HIV/AIDS-related stigma in that, people living with HIV/AIDS lack power to stand up for their rights. Although the recently promulgated constitution guarantees protection from discrimination for any person based on any ground, discrimination of rights of people living with HIV/AIDS still remain rampant in the Kenyan society (National Council for Law Reporting, 2010). Going forward, there is need for strengthening the existing institutions and legislating laws and policies that will ensure the people living with HIV/AIDS are well catered for and protected against discrimination.

Laws and policies can play an important role on the war on HIV/AIDS. For instance, education on individual rights is important in helping people living with HIV/AIDS and the entire population understand the best ways to deal with people suffering from HIV/AIDS. Gruskin et al. (2013) observe that when people are enlightened on their rights and legal procedures to address grievances, they become more 
empowered in decision making and willing to participate in development-related activities. Enactment of laws and policies that protect HIV positive people can, therefore, be an effective method of enabling people living with HIV/AIDS overcome discrimination and violence that they frequently face. However, since laws are enacted for posterity, there is need for participation of key stakeholders in the legislation of such laws so as to ensure they are acceptable to the public.

\section{Methods of Combating HIV/AIDS}

ABC method. Since AIDS is an acquired syndrome, this means that the disease is not hereditary. AIDS is a fatal disease of the immune system that usually requires the active participation of an individual in activities in which bodily fluids (semen and blood) are exchanged, such as through blood products, sexual contact, and contaminated needles (Shimbuli et al., 2009; Singhal \& Rogers, 2003; Wilson, 2012). The risk of infection with HIV during sexual intercourse depends on whether the sexual partner is infected, the number of sexual partners one has, the type of sexual contact involved, the amount of virus in the blood of the infected partner, and the likelihood of an injury occurring during sexual intercourse (Nesidai et al., 2011).

Singhal and Rogers (2013) argue that ABC method is the most effective method of preventing HIV/AIDS infection if observed consistently. The ABC method stands for “Abstinence, Be faithful, and Condom use.” It seeks to promote a holistic approach of sexual behavior with an emphasis on fidelity, fewer sexual partners, and complete sexual avoidance for the yet-to-be-married in the society. The ABC method has proved to be successful in reducing HIV/AIDS prevalence. For instance, the method assisted in a 10\% drop in the prevalence of HIV cases in Uganda between 1990 and 2001 (UNICEF, 2013). According to Barnett and Whiteside (2006), most people are aware of AIDS and HIV, but 
do not perceive themselves as at risk of infection. Thus, most people care less about taking necessary steps to protect themselves during sexual intercourse. Condoms have been scientifically proven to offer a biological buffer to prevent sexually transmitted infections such as HIV, syphilis, hepatitis B, gonorrhea, and chlamydia. Some of these diseases are not only a major cause of infertility, but are also life-threatening (Nesidai et al., 2011). Although condoms are effective barriers, their use requires a sustained behavioral change (Barnett \& Whiteside, 2006; Shimbuli et al., 2009). It is not clear therefore, why despite the efforts by the Kenyan government to distribute condoms free of charge to the public, cases of new infections still continue to be reported.

A study conducted in a Kenyan public university found that the youth are aware that condoms help to reduce the risk of HIV infection and see them as effective, but still engage in unprotected sex especially when drunk or under the influence of drugs (Nesidai et al., 2011). In another study carried out among adolescents in Nairobi by Kenyatta National Hospital, researchers observed that the youth engaged in sex with multiple partners without using condoms (Nesidai et al., 2011). This was also observed in Nigeria, where a similar study found that adolescents start engaging in sex with multiple partners at a relatively young age (Shimbuli et al., 2009). Also, Mahat, et al. (2014) observed that, although premarital sex is forbidden in Nepal, adolescents still engage in it, as a way of proving masculinity. These findings reinforce those of Qiao (2011), who found that, although people are aware of HIV/AIDS and its effects, they still engaged in unprotected sexual activities. The motivation of this risky sexual behavior is however not clear. These observations also indicate the need to shift the focus of the HIV/AIDS campaigns from an abstinence approach to other preventative methods that acknowledge that most unmarried 
people in the society engage in risky sexual activities that predispose them to HIV infection.

Male circumcision. Male circumcision is the newest method that compliments the ABC strategy. Previous studies in the past two decades have shown that male circumcision offers protection against HIV/AIDS and STIs in unprotected sexual intercourse (Mwandi et al., 2012). In a study involving 19,840 individuals in Kenya, Mwandi et al. found that HIV infection prevalence was higher in uncircumcised men at $13.2 \%$ as compared to $3.9 \%$ of the circumcised men. Although male circumcision can help prevent HIV infection, Mwandi et al. note that $13 \%$ of the male population in Kenya was not circumcised by 2009, and, incidentally, the majority of the uncircumcised men lived in the areas leading in HIV/AIDS infection. There is little extant research into how Kenyans perceive male circumcision. There is a need for more advocacy of male circumcision, especially in areas badly hit by HIV/AIDS so as to reverse the trend in infections.

Some circumcision practices contribute to the increase in HIV/AIDS infection. In Kenya, circumcision is often performed during adolescence. However, in the rural areas, circumcision is mostly conducted at home by traditional attendants. This practice is associated with bleeding and infection, especially where unsterilized surgical equipment is used on multiple initiates (Mwandi et al., 2012). The inception of national guidelines on how circumcision should be carried out would therefore help to ensure hygiene during circumcision. Some of the ways in which the Kenyan government can prevent further infections during circumcision is by training those involved in conducting initiation and availing more equipment, such as blades, so as to prevent sharing of surgical instruments 
that could lead to infection. It is also important that the Kenyan government encourage communities to promote circumcision should take place in health centers, as this would help to ensure the practice occurs in sterile environment and also reduce the risk of death among initiates in case of excessive bleeding.

Education. Education plays a key role in the fight on HIV/AIDS through promotion of gender equality and the creation of equal opportunities for men and women. Education emancipates women from traditional gender roles that have been blamed for the high HIV/AIDS infection in women, by promoting their dependence on men even in sexual matters (Abate, 2008). Treatment education is key to enabling people living with HIV/AIDS keep current on medication use and overcome the side effects of ART treatment. Education also plays an important role in shaping beliefs, knowledge, and attitudes of people towards HIV/AIDS and helping them build knowledge on how to prevent infection and change risky sexual behaviors (Abate, 2008; Aggleton, Yankah, \& Crewe, 2011; Ngula \& Miller, 2010; Thanavanh, Harun-or-Rashid, Kasuya, \& Sakamoto, 2013). Aggleton et al. (2011) observed that education and participation equip development partners with decision-making mechanisms that lead to empowerment and strong relationships that are vital in the fight against HIV/AIDS, especially in developing countries.

Aggleton et al. (2011) argue that education serves as a tool of controlling HIV/AIDS when it boosts people's capability to protect themselves from the pandemic, but fails if it does not challenge myths and deceptive beliefs that have contributed to the spread of HIV/AIDS. When literacy rate is high in the society, people tend to have high capability to deal with emerging diseases, but low literacy levels hinder a society from 
addressing its health problems. Muturi and Mwangi (2011), for instance, contend that low literacy levels in rural areas and inadequate education components in most HIV/AIDS campaigns are the main reasons for the spread of HIV/AIDS in rural Kenya. A similar view is propagated by Oluga et al. (2010) who posit that discussion of sex-related topics with young people, especially girls, is seen as immoral and indecent in Kenya and Tanzania, with parents opposing education on sex and contraceptives in schools in both countries, as they view this as a way of encouraging immorality in their children. Most often, HIV/AIDS is not taught openly in schools for fear of backlash from key educational stakeholders such as parents and religious leaders (Aggleton et al., 2011; Njue, Nzioka, Ahlberg, Pertet, \& Voeten, 2009). Further, Mahat et al. (2014) contend that negative perceptions of sexual topics create a culture of silence, in which teachers and students shy away from discussing sexual topics and sexually transmitted infections, leading to further spread of the disease and new infections. This impedes the control of HIV/AIDS, considering most of those affected by the pandemic are the youth. Going forward, there is need for the government and other education stakeholders to encourage open dialogue about sex and other practices that predispose people to STIs and HIV/AIDS as a way of building the society's capability of preventing such infections. This will also help to address stigmatization of HIV/AIDS and people living with this pandemic.

In a study of 21 primary and nine high schools in Kenya, Njue et al. (2009) found that AIDS curriculum has been implemented and most students reported having received lessons related to HIV/AIDS. However, Njue et al. also observed that the curriculum relies more on physiological information about HIV/AIDS, but does not offer skills to 
students on how to protect themselves from the disease, nor addresses social-cultural issues such as gender, sexual orientation, and correct use of condoms. Njue et al. identified mistrust between students and teachers as a major impediment in AIDS education in Kenya, making students reluctant to share personal sex lives with teachers for fear of breach of confidentiality.

Considering the pivotal role of education in not only controlling HIV/ADS in the society, but also in equipping learners with skills that can help them protect themselves from other diseases, it is important that the Kenyan government invests more resources in education. It is also necessary that the government looks for better ways of integrating HIV/AIDS education in the general curriculum, and create more awareness as a way of controlling stigma associated with discussing sexual topics in schools.

Community engagement. The AIDS campaign has recently shifted focus to community engagement, as communities are seen as better positioned to address problems in their environs and address the limitations of education-only approaches used previously (Patel, 2005; Richman et al., 2013). A community-centered participatory approach contextualizes communication as the process of sharing knowledge and meanings among stakeholders and recognizes the importance of engaging the target audiences in designing and implementing the health projects (Muturi \& Mwangi, 2011). Community engagement is premised on the belief that building the capacity of a society to deal with emerging problems is more effective than imposing extrinsic solutions to those problems.

Patel (2005) argues that community engagement entails partnerships, diversity, and participation so as to achieve the set campaigns' objectives. Therefore, in the Kenyan 
context; HIV/AIDS campaigns should include key stakeholders, so as to create synergy in networks through which information can be communicated. The HIV/AIDS campaigns should also bring together individuals with a wide range of interests, strengths, opinions, religion, and status, and involve them in the design and implementation of the campaigns. This will help to create a common identity, instill a sense of ownership, and mutual direction in the identified projects, and increase the chances of success of the HIV/AIDS campaign.

Community engagement is premised on social mobilization and the belief that when key stakeholders are involved in campaigns, success can easily be realized. "Social mobilization is the process of bringing together multi-sectoral community partners to raise awareness, demand, and gauge progress for the initiative’s goals, processes, and outcomes” (Patel, 2005, p. 93). More than half of people (65\%) in Sub-Saharan Africa reside in the rural areas. The HIV/AIDS prevalence in the rural areas tend to be low, but local families bear the burden of people living with HIV/AIDS in urban areas coming home to die when overwhelmed by the disease (Campbell, 2010). Muturi and Mwangi (2011) observed that, although HIV/AIDS campaigns are conducted nationally, adequate information on the campaigns was lacking in the rural communities in Kenya, and the government was not availing more information on the severity of the disease. This thesis argues that community engagement should include the people with HIV/AIDS so as to enhance credibility of their efforts, as well as help to address stigmatization of people living with HIV/AIDS.

Community engagement has played a key role in increasing HIV/AIDS sensitization, women empowerment, and adoption of prevention strategies in most parts 
of Kenya (Richman et al., 2013). Local leaders should be involved in community mobilization since they are known by other members of the community, unlike external experts (Campbell, 2010). Involving communities in health campaigns increases the chances of success in such projects, because it inculcates a sense of ownership in the target communities as they feel valued, since their views are taken into consideration, and so are motivated to adopt the proposed health interventions. To enhance community involvement, local initiatives require external facilitation so as to increase the capacity of the local communities to find solutions to the HIV/AIDS pandemic through provision of resources and requisite knowledge (Singhal \& Rogers, 2003).

However, local leadership can be a hindrance to the war on HIV/AIDS, especially if leaders are resistant to the adoption of new ways that challenge the society's cultural and religious beliefs suggested by health experts (Campbell, 2010). In a case study in South Africa, a project designed to empower women and girls to adopt safe-sex practices failed to achieve its set goals due to interference by the local traditional chief, who encouraged polygamy and discouraged use of condoms (Campbell, 2010). This greatly impeded the success of the HIV/AIDS campaigns, which at the time were majorly anchored on fidelity and monogamous relationships. Richman et al. (2013) noted that community engagement achieves effectiveness if there are national policies that support local activities. Although most HIV/AIDS campaigns in Kenya involve the opinion leaders in the communities, there is need for increasing areas of cooperation between the government and local communities as a way of boosting the war on HIV/AIDS. Specifically, there is need for using community engagement to create more HIV/AIDS 
awareness, discourage cultural practices that predispose people to HIV infection, and encourage tolerance for people living with HIV/AIDS.

\section{An Evaluation of HIV/AIDS Campaigns}

\section{Fear Appeals}

Most public communication uses fear appeals in HIV/AIDS-related messages, portraying HIV/AIDS as a dreadful disease spread through immoral sexual practices (Muthusamy, Levine, \& Weber, 2009; Singhal \& Rogers, 2003). Fear appeals trigger cognitive appraisal based on perceived susceptibility and severity. Use of fear appeals to scare the public to adopt healthy lifestyles helps to catch the attention of the audience, but does not necessarily change their behavior, especially when preexisting fear about a threat is already high (Muthusamy et al., 2009; Wilson, 2012). Therefore, it is reasonable to infer that most HIV/AIDS messages fail if solely based on fear appeal, because HIV/AIDS is still a dreaded and stigmatized disease.

Muthusamy and colleagues (2009) define perceived severity as the extent of the magnitude of a threat, while perceived susceptibility is the extent to which one views him/herself as vulnerable to infection. As the level of perceived susceptibility and severity increases, fear also increases. Muthusamy et al. contend that when self-efficacy exceeds the level of perceived threat and susceptibility, an adaptive response is elicited leading to the adoption of a coping behavior, whereas a perceived threat that is viewed as higher than efficacy levels elicits maladaptive responses, which take the target audience further from the advocated position. There is need, therefore, to use fear appeals in HIV/AIDS campaigns with caution, to ensure the messages do not scare the target audience to a point where they feel incapable of dealing with the perceived threat. 
Indiscriminate use of fear appeals without offering danger control techniques to the audience is one of the reasons why health campaigns fail to achieve the set goals (Perloff, 2014; Wilson, 2012). Public health messages are more effective when communication strategies are consistent with the target audience cognition. The way health messages are crafted and delivered, determines the acceptability of the proposed behavior change (Ahmad, 2005; Okidu, 2013). Kreuter, Farrel, Olevitch, and Brennan (2000) contend that when messages are tailored to suit the needs of an audience, the audience is more likely to relate the messages to their past and present experiences and adopt them into their lives. Kreuter et al. attribute the success of well-designed messages to the fact that customizing them helps to eliminate superfluous information and focus the relevant details to the attention of the audience, which could facilitate behavior change.

Ahmad (2005) argues that HIV/AIDS is unlike other diseases that are easily contained through curative means, because it is has continuously defied control efforts. Thus, there is a need to explore ways to enhance HIV/AIDS campaigns to ensure they achieve the set goals and encourage change of risky sexual behaviors that predispose people to infection. The rate of behavior change is a product of effective communication efforts and availability of the advocated products and services that reinforce the change. Behavior change is only possible if the recommended behavior is relevant and meets the needs of the target audience (Ahmad, 2005; Wilson, 2012). The change is influenced by two types of factors; push and pull. Ahmad defines push factors as personality-based factors such as personality traits, status in the society, and self-driven motivation, and pull factors as environmentally based, such as peer influence, legal frameworks, and financial ability to access the intended products, opinion, and religious leaders. 
Communication plays an indispensable role in behavior change, especially in creating awareness of societal problems and transmitting information about the adoption of the intended change and how it can be sustained (Ahmad, 2005). Behavior change in individuals precedes social change in the society; thus, if one intends to change behavior in a society, he/she should start first by targeting behavior change in individuals. Ahmad defines social change as an interactive process where the community dialogue occurs, leading to a collective action, which produces change in a community and improves the welfare of its members. Social change is more effective when there is dialogue in a community about a problem, leaders are involved in the change, and the community is given a chance to prescribe solutions to their problems. Consistent with Ahmad's argument, this thesis advocates for increased involvement of stakeholders in HIV/AIDS campaigns, and tailoring of messages to encourage personal behavior change, since this will translate to a more open and healthy society.

\section{Entertainment Education in HIV/AIDS Messages}

Most of the media-related HIV/AIDS campaigns in Kenya rely on entertainment education. Entertainment education (EE) refers to the use of creative messages in the media in health or development-related campaigns, to entertain the target audience, while at the same time, promoting prosocial behavior in the society through creation of awareness (Singhal \& Rogers, 2003). For a campaign to qualify as EE, aspects of both entertainment and education must be incorporated in the same message (Mahoney \& Bates, 2013; Singhal \& Rogers, 2003). Singhal and Rogers argue that EE involves formative research, audience analysis, a multimedia approach, and animation in behavior change campaigns. Thus, the purpose of EE is usually to persuade the target audience to 
adopt an advocated behavior using characters who appeal to them, while at the same communicating the intended messages.

Elements of entertainment education campaigns. Certain components of EE are vital to the success of any campaign that uses EE. These are the use of a values grid and formative evaluation research. A values grid draws from the laws, religious beliefs, and norms of the target society and ensures consistency of the campaigns' storyline with the goals of the EE campaign. It also adds credibility to the health campaign by bringing on board key stakeholders, thus preventing later attacks on the advocated interventions (Singhal \& Rogers, 2003).

On the other hand, formative evaluation research is conducted during the design of a campaign so as to improve its effectiveness (Rogers et al., 1999). It involves an analysis of the target audience and selection of the strategies that best ensure the success of the campaigns (Singhal \& Rogers, 2003). Formative evaluation research ensures that the attitudes and perceptions of the target audience are addressed, so as to prevent a boomerang effect on the campaign (Tindall \& Vardeman-Winter, 2011). In South Africa, for instance, Singhal and Rogers (2003) observed that an HIV/AIDS campaign worth \$2.5 million dollars, commissioned by the Ministry of Health in 1994, rebounded due to several errors at the design stage and the failure of the campaign designers to consult health professionals, thus, the messages did not resonate with the target population. Singhal and Rogers argue that formative evaluation ensures the pitfalls of the campaign are identified and avoided well before the campaign is rolled out. EE can be strengthened by continuously gathering data about the effectiveness of an intervention program while it is still underway. 
The growth of entertainment education. EE is not a new concept and draws from the art of storytelling, music, drama, and dance that have been used for ages for recreational and instructional purposes (Singhal \& Rogers, 2003). Singhal and Rogers (2003) argue that the rise of EE is credited to the British Broadcasting Corporation (BBC), which, in 1951, started broadcasting radio soap operas to convey agricultural messages. Early forms of EE are also traceable to Peru, where a soap opera of the 1990s, Simplemente Maria, depicted the plight of women through the main character, Maria, who worked during the day and sewed at night, using the Singer sewing machine to make ends meet. The soap opera led to an increase in girls' enrollment in high schools, because it encouraged girls to climb the social and economic ladder and to compete with their male counterparts. Simplemente Maria also gained high audience viewership and ratings, which led to high sales of the Singer sewing machine. Thus, besides the soap opera inspiring girls, it also helped to brand Singer sewing machine, and this reveals the power that entertainment education has if harnessed properly.

Singhal and Rogers (2003) posit that the success of Simplemente Maria in Peru inspired EE in Mexico, where it was used to promote education and contraceptives, resulting in an increase in adult literacy, gender awareness, and adoption of family planning programs. Ever since, EE has grown and been adopted in several campaigns across the globe. However, EE has metamorphosed and presently focuses on the participatory aspects of the audience, due to the realization that antisocial behavior is not a result of knowledge gaps, but power and structural inequalities in the society (Mahoney \& Bates, 2013). EE has successfully been used in many HIV/AIDS campaigns in Africa such as the Soul City in South Africa and Twende na Wakati, a Swahili show aired in the 
Kenyan media that means, "let us go with the times” (Singhal \& Rogers, 2003). EE is used extensively in the Kenyan media programs on television and radio to promote safesex practices such as use of condoms, voluntary testing, and counseling (VCT), and faithfulness in marriage. These programs have relied highly on local celebrities that the public can identify as a way of enhancing behavior change in the target population.

Importance of entertainment education in health campaigns. EE has the ability to model an individual's and society's efficacy by shaping perceptions and boosting capability to handle problems (Singhal \& Rogers, 2003). For example, Mahoney and Bates (2013) in their study on the impacts of radio drama series on HIV/AIDS in Botswana, found that those who followed the drama series reported change of stigmarelated perceptions and improved knowledge on HIV/AIDS than those who did not listen to the program at all.

Mahoney and Bates (2013) argue that EE aims at imparting the right behavior and attitudes in the target population by utilizing the popular nature of entertainment in the campaign messages. Presently, most of the entertainment education campaigns are communicated through television and radio programs using health or development related themes, with the sole aim of changing the behavior of the target audience. Singhal and Rogers (2003) contend that EE is an effective way of running health-related campaigns, because of its prosocial characteristics that enable the target audience to identify with the message in a better way that traditional media cannot achieve. This is achieved through the use of characters in the campaigns with whom the target population can easily identify with, thus increasing the chances of behavior change (Mahoney \& Bates, 2013; Singhal \& Rogers, 2003). 
EE is a viable tool in HIV campaigns because it engages the audience by appealing to their emotions and encourages discourse on socially taboo topics such as HIV/AIDS. EE also creates a more open environment for social change, in which the audience can engage in positive and healthy dialogue on a campaign issue, hence increasing the propensity of adopting the advocated behavior (Mahoney \& Bates, 2013; Singhal \& Rogers, 2003). For instance, use of soap operas, Soul City in South Africa, helped to promote behavior change and tolerance for people living with HIV/AIDS (Hutchinson, Mahlalela, \& Yukich, 2007). Therefore, it is evident that EE can be a viable tool to fight HIV/AIDS stigma and create more awareness about the disease if utilized effectively.

One of the ways through which EE can be used in HIV/AIDS in Kenya, is through its incorporation in music. Van Buren (2011) argues that music is effective in passing messages in Africa, due to its long history of use in the continent, thus its incorporation in AIDS messages would greatly make such information more appealing. Rogers et al. (1999) aver that entertainment in Africa, plays an effective role in imparting knowledge in the audience and motivating the target audience to join programs that support behavior change. Use of music and radio messages to transmit HIV/AIDS messages would particularly be useful to reach the rural communities, who have limited access to television sets and the Internet.

Van Buren (2011) notes that musicians have been active in the promotion of AIDS campaigns in Kenya, through art to communicate HIV/AIDS-related messages. Most of these musicians reside in urban centers, but through collaborations with other organizations, tour different parts of the country to perform. Kenyan schools also 
organize music festival contests that bring together students from all over the country.

The purpose of these festivals is to foster artistic development in students and communicating educational themes mostly in health, economy, and general social issues. These festivals can be effective to communicate HIV/AIDS messages, if they incorporate elements of EE, to entertain the audience while at the same time advocating for behavior change among the audience.

It is clear that there exists a broad set of platforms in Kenya that can be used to communicate HIV/AIDS-related messages. However, these channels are underutilized, therefore, there is a need for all of these channels to be harnessed and synchronized to ensure uniformity in transmission of AIDS messages. This will greatly boost the war on HIV/AIDS.

\section{Effects of HIV/AIDS on Development}

Despite the international efforts aimed at addressing overall development needs, HIV/AIDS stands as a global challenge affecting education, social, and economic status of people as well as other human aspects such as human rights (Boutayeb, 2009). "Socially, the HIV/AIDS pandemic causes stigma and discrimination, and places burdens on governments, families, educational institutions, and health care organizations” (Patel, 2005, p. 91).

Although the rate of infection has decreased, the number of people infected with HIV/AIDS in Sub-Saharan Africa has increased and many people infected with HIV/AIDS do not have adequate access to HIV/AIDS-related treatment in most developing nations (Moradi et al., 2011). Moradi and colleagues (2011) argue that, out of an estimated 15 million people infected with HIV/AIDS in developing nations, only 5.2 
million have access to treatment. By 2009, there were 16 million orphaned children as a result of HIV/AIDS in Sub-Sahara Africa. Two-thirds of all HIV positive people and three-quarter of AIDS related deaths occur in Sub- Saharan Africa, this has a big impact on the lives of surviving relatives (Chicoine, 2011; Langat, Falkingham, Madise, \& Evandrou, 2012). This is a clear indicator of the magnitude of impact that HIV/AIDS pandemic has on the economies of the nations in this region.

Besides leading to death of the workforce and family members, HIV/AIDS increases the cost of production and in the long run has the potential of reducing economic growth (Boutayeb, 2009; Chicoine, 2011). Good health can be a major contributor to economic prosperity, as it promotes labor productivity. As workers' health deteriorates due to HIV/AIDS infection, their productivity decreases; this is evidenced by long hours of absenteeism, as they seek medication and rest at home, when the effects of the disease take toll on their health (Dodd \& Cassels, 2006; Moradi et al., 2011). The HIV/AIDS pandemic also reduces life expectancy, thus hindering development of human resources by both individuals and organizations, since the acquired skills may not be fully utilized if the infected persons die before reaching their full potential (Boutayeb, 2009; Frölich \& Vazquez-Alvarez, 2009; Okidu, 2013). Thus, the war on HIV/AIDS should be taken seriously, as the pandemic poses a threat to not only its victims, but nations as well.

More than half of all hospital bed capacity of public hospitals in Sub-Sahara Africa are occupied by patients of HIV/AIDS-related diseases (Boutayeb, 2009). The HIV/AIDS pandemic increases the risk of infection by other diseases such as diabetes, heart disease, and tuberculosis. However, it is difficult to establish the actual number of 
people killed by HIV/AIDS, because the disease weakens the immune system, therefore, death of victims is often attributed to other infections (Chicoine, 2011).

Education in Africa is also negatively impacted by the HIV/AIDS pandemic. In Africa, less than $65 \%$ of the children are enrolled in primary schools, and thousands of them drop out of school due to HIV/AIDS-related pressure either because they are orphaned, or to help look after the infected members of their families (Boutayeb, 2009; NACC \& NASCOP, 2014). This partly explains the reasons for the high rates of illiteracy in Sub-Saharan Africa. Aggleton and colleagues (2011) argue that education plays an important role in shaping beliefs, knowledge, and attitudes; it is, therefore, arguable that when school dropout rates are high, people lack basic knowledge, making it difficult to persuade them into adopting safe-sexual practices. This is a great impediment to the war on HIV/AIDS.

The HIV/AIDS pandemic can also lead to food shortage in the family, especially where the person infected with HIV/AIDS is the breadwinner (Nageta et al., 2012). Nageta and colleagues (2012) note that many HIV/AIDS-positive people living in rural areas in Kenya go without food due to drought and famine affecting these regions, and this can lead to risky coping strategies such as sex for money, and, because ARVs should be taken with food, those who lack food are forced to go without medication. This is not only a life-threatening situation for the victims, but also a hindrance to the control of the HIV/AIDS pandemic. 


\section{Millennium Development Goals}

In 2000, the international community through the United Nations (UN) resolved to eradicate poverty and improve health in the world's poorest countries within 15 years. The resulting commitments came to be known as MDGs (Dodd \& Cassels, 2006). MDGs were developed by the UN member states to address development issues in underdeveloped countries (Bernardi \& Chiara, 2011). The MDGs offer a benchmark for development and have received acceptance from both the developed and developing countries. MDGs are also important strategic tools for promoting human development and political commitment by leaders at the global level (Moradi et al., 2011).

In 2001, during the $26^{\text {th }}$ special session of the General Assembly of United Nations, member states adopted a declaration of commitment on HIV/AIDS to address the growing threat posed by the pandemic, which at the time had infected 36.1 million people across the globe, with 75\% of the victims residing in Sub-Saharan Africa (Bernardi \& Chiara, 2011). Bernardi and Chiara (2011) noted that the declaration led to setting up of millions of dollars in grants such as the Global Fund and the US President's Emergency Plan for AIDS Relief (PEPFAR) to assist developing countries address health challenges posed by malaria, HIV/AIDS, and tuberculosis. The largest share of foreign aid to the developing countries has been in health activities aimed at fighting HIV/AIDS and malaria. HIV/AIDS was declared a national disaster in Kenya in 1999, leading to the creation of the National Aids Control Council (NACC) to coordinate the efforts aimed at controlling the disease, and since then, the Kenyan government, together with other development partners such as NGOs, has utilized many interventions aimed at controlling the disease. 
Health, in general, is at the center of the MDGs and is identified as a significant factor in poverty reduction and a measure of general human wellbeing (Dodd \& Cassels, 2006; Moradi et al., 2011). This is because when people are healthy, then they can participate in economic, social, and political activities that uplift their lives, as well as the lives of their communities. Most of the MDGs that were set, however, have not been actualized. Fehlinga, Nelson, and Venkatapuramd (2013) contend that the progress of the MDGs is uneven across nations and attribute the failure of the MDGs to the lack of commitment from member states, inadequate resources, lack of adequate political will, inadequate accountability and transparency, and poor design of the goals, in that there was minimal involvement of the developing countries in the creation of the goals. Further, Donald and Cassels (2006), posit that health-related MDGs were lagging behind other goals in terms of implementation, especially in developing countries, because of the fact that, developing countries, unlike developed nations, face enormous challenges ranging from inadequate prioritization of health, weak health systems, poor management of health records, and insufficient monetary resources to fund health-related goals. Other scholars (e.g. Easterly, 2008) argue that in Africa, almost all of the MDGs have failed, because they were designed to gauge development against poverty, thus most of the progress realized in Africa looks like failure when measured against the MDGs. Taken together, these arguments suggest that the MDGs would have been more successful had the process of their formulation involved more stakeholders, and the goals been more inclusive, realistic, measurable, and specific.

However, although the MDGs have failed, the war on HIV/AIDS is not yet lost. The global community has renewed its commitment to achieving equitable development 
and boosting health standards in developing countries by 2030, through new goals under the umbrella of sustainable development goals. The third sustainable development goal is dedicated to health, and in regards to the present thesis, the eradication of HIV/AIDS by 2030 (United Nations, 2016). In 2015, when HIV/AIDS ought to have been eradicated through the MDGs, the UN noted the following:

At the end of 2014, there were 13.6 million people accessing antiretroviral therapy, 240000 children were newly infected with HIV, adolescent girls and young women face gender-based inequalities, exclusion, discrimination and violence, which put them at increased risk of acquiring HIV, which remains the leading cause of death for women of reproductive age worldwide. There were 250, 000 new HIV infections among adolescents in 2013, two thirds of which were among adolescent girls, and that AIDS is now the leading cause of death among adolescents (aged 10 - 19) in Africa and the second most common cause of death among adolescents globally. (United Nations, 2016).

These findings by the UN indicate that HIV/AIDS remains a threat to global health and that much remains to be done, even after the lapse of the deadline of MDGs. The present study therefore addresses the achievements made to contain the pandemic in Kenya so far and offers suggestions into what ought to be done to sustain the momentum gained in the war on HIV/AIDS.

\section{Theoretical Framework}

This study is grounded on diffusion of innovations theory (DOI), which was first postulated by Rogers in 1962. DOI's main premise is that behavior change in a society can arise internally or externally, through contact with outside forces (Rogers, 2003). The theory explains how, over time, an idea gains momentum and spreads, or diffuses through 
a population or in a social system, with the end product being adoption of the new idea or behavior as part of the social system. Rogers (2003) defines diffusion as the process in which innovation is introduced to the society through various communication channels over time. Adoption is defined as the decision by individuals to fully integrate an innovation into their daily lives (Weigel, Hazen, Cegielski, \& Hall, 2014). An innovation diffuses faster when the source of information is credible, the innovation is perceived as better than the prevailing ideas or in tandem with the societal values, and the diffusion can easily be tried before adoption (Barker, 2004; Farr \& Ames, 2008).

The diffusion of innovations is perceived to be a social process that takes place through interaction among members of the society (Backer \& Rogers, 1998). DOI as a theory, recognizes social systems as powerful in dissemination of innovations, especially in enabling members of the society to share information freely (Farr \& Ames, 2008). Langat and colleagues (2012) argue that social networks influence sharing of information, shaping of attitudes, and how audiences perceive information. To assess the potential for information exchange in a system, one should consider the existing interaction of members in the system. Farr and Ames observed that strong links in a social system are characterized by contacts with key people and organizations, as well as group discussions that occur in a respectful and trustworthy environment.

Haider, Pal, and Al-Shoura (2005) argue that DOI involves the following stages: knowledge, persuasion, decision, implementation, and confirmation. Knowledge is acquired when an individual is introduced to a new idea and starts acknowledging it as important and makes an effort to gain understanding of the idea. During persuasion, target audience members start to develop negative or positive attitudes toward the new 
idea and this influences whether they adopt or reject the new idea, based on cost-benefit analysis. lastly, implementation occurs when an individual adopts the new innovation into her/his life and confirmation occurs when a person makes an effort to seek information that reinforces adoption of the new idea. The HIV/AIDS campaigns in Kenya should aim at creating more awareness and educating the public on the risk factors that predispose them to infection and how they can protect themselves from such infections. Creation of more awareness and educating the public would also help to create more capacity on the part of the society to deal with problems associated with the HIV/AIDS pandemic and encourage open dialogue about the scourge that continue to claim lives, and hopefully encourage behavior change.

DOI classifies people into innovators, early adopters, early majority, late majority, and laggards (Rogers, 2003). Innovators adopt new ideas right at the beginning when they are introduced. These people form a small portion of a target society and are usually open-minded and well educated. Early adopters are less adventurous compared to innovators but are generally open-minded. The early majority adopt an innovation before the average population but right after the early adopters. The late majority usually adopt an innovation after the early majority and usually as a result of peer pressure. Laggards are usually suspicious of the new idea and, as a result, take a long time to adopt an innovation. Most people do not evaluate a proposed innovation on scientific basis but instead depend on people in their social networks who have already adopted the innovation (Haider et al., 2005; Rogers, 2003). If the innovation is perceived to have relative advantage by early adopters, there tends to be an increase in adoption as the early adopters share their experiences with potential adopters (Backer \& Rogers, 1998). 
DOI theory has been used to promote ideas, sell products, and influence societies and nations at large (Farr \& Ames, 2008; Haider et al., 2005). According to Haider et al. (2005), DOI postulates that societies are always resistant to change. Thus, it requires agents of change to drive diffusion by communicating to the target society why a change is necessary. Diffusion occurs at a slow pace owing to its inherent uncertainty as it involves an alteration in the initial structure of the society through introduction of new ideas. For instance, it took more than 150 years for the British navy to adopt citrus fruits as treatment for scurvy even though initial experiments had proved the fruits were effective in treating the disease (Rogers, 2003). The delay in adopting an innovation that had been proven effective led to the death of hundreds of British sailors. An innovation can be rejected if perceived as against the prevailing beliefs and cultural practices. Rogers (2003) noted that in a Peruvian village, for instance, a health campaign aimed at encouraging locals to boil drinking water failed because it was perceived as inappropriate to the local culture that links boiled water to sickness and weakness, thus only fit to be consumed by the ailing members of the society.

According to DOI theory, involving opinion leaders who have surmountable levels of trust in the community, helps to ensure that the target audience do not reject what the campaign advocates for from the start (Barker, 2004). Opinion leaders are found at different levels in the social system and are considered brokers of influence since they play an important role in persuasion, especially between groups (Farr \& Ames, 2008). For example, Barker (2004) observed that use of voodoo practitioners in Haiti to teach HIV education in remote rural areas helped to mobilize the target audience and led to an increase in the number of participants in the project and enhanced the receptivity of the 
HIV/AIDS messages. In an attempt to promote consumption of foods rich in vitamin A in Nepal, USAID used select households to demonstrate to the villagers how to grow vegetables in kitchen gardens with the hope that neighbors would emulate these households because of improved health. Barker observed that, within two years of the project, the villagers had adopted the project by tenfold, and incidences of night blindness reduced by $66 \%$ among pregnant women in these households. It is evident, therefore, that trusted opinion leaders can influence how the target audience perceive a health campaign and can enhance the success of such campaigns.

Haider et al. (2005) describe the use of young men as change agents by Guy-toGuy, a project by a Brazilian NGO, to address the growing incidents of gender violence against women. The project involved 749 men (15-60-year-olds) from low socioeconomic families in Rio de Janeiro, where gender-based violence was most prevalent. The innovation used in this project was education to counter stereotypes that perpetuated male chauvinism and, as a result, predisposed men to perpetrate violence against women. After the training, the volunteers in this project, under the guidance of their educators, shared the knowledge they had acquired with their peers in their social networks. The project was a success as men learned to respect women, leading to more awareness about domestic violence among men in the area and a significant drop in reported gender-based violence.

The DOI theory has been successful in promoting health campaigns such as adoption of contraceptives and safe-sex practices in developing nations and thaw strong religious beliefs that counter the purpose of a health campaign (Haider et al., 2005). In the Philippines, for instance, a project by the Department of Health to encourage family 
planning between 1993-1996 saw an increase in contraceptive use from 40\%-48\%, despite the strong stand taken by the Catholic Church. To counter the strong opposition of family planning by the Catholic Church, the Department of Health designed campaigns that portrayed contraceptives not as a barrier to having children, but as a way of ensuring that each pregnancy was well-planned for and children were better taken care of. The Philippines’ Department of Health used both mass media and interpersonal communication to promote messages on the importance of family planning. This helped to ensure that the health messages reached a large audience. Mass media messages also featured health professionals as well as actual contraceptive users to relay the messages, thus presenting family planning as credible and effective in preventing unwanted pregnancies. As the early adopters began using contraceptives, the decrease in unwanted pregnancy became evident, motivating more people to adopt family planning. Through mass media and interpersonal communication, many couples became aware of the benefits of family planning, resulting in its adoption. This convinced late adopters of the importance of family planning resulting to widespread family planning practice.

The success of new interventions is influenced by the following factors:

\section{Relative Advantage}

What new benefits does the advocated idea bring over the existing situation? Relative advantage is mainly concerned with economic aspects such as affordability, convenience, and satisfaction (Rogers, 2003). The bigger the perceived advantage, the faster the rate of adoption of the proposed change. 


\section{Compatibility}

This refers to the extent to which the proposed innovation fits with already existing beliefs, values, and needs of the target audience (Rogers, 2003). An idea that contradicts these will not be easily adopted, but an idea that is compatible is rapidly adopted.

\section{Complexity}

This is the extent to which the proposed change is difficult to comprehend. The simpler an innovation, the faster it diffuses because people easily understand what it entails.

\section{Trialability}

Trialability refers to the extent to which the proposed innovation can be implemented on a limited basis. Ideas that can be implemented on a small scale by the target society are more easily adopted (Rogers, 2003).

\section{Observability}

This is the degree of visibility of the results of innovation to others. Visibility increases the rate of adoption of innovation as it arouses discussion among peers and friends, leading to the subsequent adoption of the new invention (Rogers, 2003).

\section{Current Study, Research Questions, and Hypotheses}

While the Kenyan government has invested immense resources in the HIV/AIDS war, the new rates of infection remain high. It is clear that Kenyans are aware of the risk of engaging in sex with multiple partners, unprotected sex, and the danger posed by HIV/AIDS. Previous studies attribute the rising rate of HIV/AIDS to factors such as deceptive cultural beliefs, religion, misinformation, stigma, and poor laws and policies 
(Chang et al., 2013; Singhal \& Rogers, 2003; Wilson, 2012; Yuh et al., 2014). HIV/AIDS is a global problem, the control of which lies in how best to mitigate the effects of the above factors. This study therefore proposes the following research question to establish knowledge on factors that contribute to the spread of HIV/AIDS:

$\mathrm{RQ}_{1}$ : What is the level of HIV/AIDS knowledge portrayed by Kenyans on the factors contributing to the high rate of infection and spread of HIV/AIDS in Kenya?

Ahmad (2005) argues that the design of health messages determines success in influencing the target audience. This implies that, it is possible that the way HIV/AIDS messages are communicated in Kenya makes them less effective. Perloff (2014) argues that health messages can fail if they arouse too little fear or too much fear. People suffer from illusion of invulnerability; thus, they view other people as susceptible to infection but not themselves. To establish the perceptions of Kenyans regarding efficiency of present interventions, the present study therefore proposes the following research question:

$\mathrm{RQ}_{2}$ : What are the perceptions of Kenyans towards the effectiveness of various health communication interventions used in the control of HIV/AIDS in Kenya? Based on previous studies, the present study also hypothesizes the following: $\mathrm{H}_{1}$ : Age does not predict the level of knowledge of HIV/AIDS among Kenyans. Previous studies identify stigma as one of the impediments to the war on HIV/AIDS. Throughout the world, HIV/AIDS is stereotyped as a disease for the sexually immoral (Singhal \& Rogers, 2003; Taylor, 2013; Wilson, 2012). This study, therefore, 
argues that overcoming HIV/AIDS stigma is one of the ways of controlling HIV/AIDS, and as a result proposes the following question:

$\mathrm{RQ}_{3}$ : What are the perceptions of Kenyans towards people living with HIV/AIDS?

The HIV/AIDS campaign messages in Kenya have not been very successful; in that they have failed to prevent new infections. The media messages on HIV/AIDS are also highly censored because of political, cultural, and religious inclinations. Media play a big role in the war on HIV/AIDS because transmission of HIV/AIDS-related information is powerful in shaping people's opinion, creating awareness, and helping to set the agenda for the health advocates (D’Angelo, Pollock, Kiernicki, \& Shaw, 2013). Scholars concur that entertainment education increases the efficacy of HIV/AIDS campaigns (Mahoney \& Bates, 2013; Singhal \& Rogers, 2003). Thus, the present study therefore hypothesizes the following:

$\mathrm{H}_{2}$ : Media are the largest single sources of AIDS information in Kenya, and most people perceive such information as more credible than information from government offices.

DOI recognizes the role played by opinion leaders; especially in ensuring the health messages are not out rightly rejected by the target community. Based on DOI theory, the present study argues that for HIV/AIDS campaigns in Kenya to be successful, there is need to involve opinion leaders. Opinion leaders in Kenya include religious and elected leaders as well as government officers who work directly with the people. The study also assesses the perceptions of Kenyans towards the credibility of HIV/AIDS information provided by the government and media. Thus, to assess the role of opinion 
leaders such as politicians, religious leaders, and community elders, this study proposes the following research question:

$\mathrm{RQ}_{4}$ : what are the perceptions of Kenyans on social networks in HIV/AIDS campaigns?

Specifically, this question has two components:

$\mathrm{RQ}_{4 \mathrm{a}}$ : What are the perceptions of Kenyans toward involvement of opinion leaders in HIV/AIDS campaigns?

DOI also recognizes the importance of community engagement and social networks to communicate about the campaign information. Therefore, closely related to $\mathrm{RQ}_{4 \mathrm{a}}$ above, the study also assesses how Kenyans share HIV/AIDS information. The study therefore proposes the following research question:

$\mathrm{RQ}_{4 \mathrm{~b}}$ : How often do Kenyans share HIV/AIDS information with friends, family, colleagues, or acquaintances?

The implementation of MDGs places the responsibility of containing the HIV/AIDS pandemic on UN member states. Previous research argue that the Kenyan government has made some effort to control HIV/AIDS through legislation, provision of free condoms and drugs, and creation of awareness (Nesidai, 2011; UNICEF, 2013). Thus, to assess the people's perception toward the involvement of the Kenyan government, this study proposes the following research question:

RQ5: What are the perceptions of Kenyans toward government efforts to address HIV/AIDS in Kenya? 


\section{Conclusion}

This chapter has examined various studies on HIV/AIDS including its effects and ways of controlling it. The chapter has also summarized the challenges experienced in fighting the scourge in Kenya. HIV/AIDS is not only a health problem but also a development issue impacting Kenya in a great way. As the deadline for MDGs has already passed, there is need for concerted efforts to sustain the war on HIV/AIDS.

The government needs to do more to eradicate impediments that reduce the efficacy of AIDS campaigns. This could be through continued consultations with key stakeholders and building capacity for those mandated with controlling the HIV/AIDS pandemic, assessing the understanding of perceptions of Kenyans on current efforts, and restructuring AIDS education in Kenya in order to align it with the current realities that hamper the war on the HIV/AIDS pandemic. The next chapter will examine the methods used to conduct this study. 


\section{CHAPTER III}

\section{METHODS}

The previous chapter explored the HIV/AIDS situation in Kenya, possible reasons for the high rate of infections, various aspects of the MDGs, and a general evaluation of the HIV/AIDS health campaigns in Kenya. Previous studies have explained a broad range of factors contributing to the high rates of HIV infection. Indeed, as the deadline for the MDGs passed without the effective control of the HIV/AIDS pandemic, there was a need to re-evaluate the approaches that have been used so far and reinvent new strategies that will sustain the momentum on the war on HIV/AIDS. This chapter explains how data were collected and the procedures followed in the present study.

\section{Participants}

A total of 407 people responded to the survey, but only 103 participants completed the survey. Specifically, out of those who completed, there were 33 females (36.3\%), 57 males (55.3\%), 1 transgender person (1\%), and 12 respondents (11.7\%) who did not disclose their biological sex. The mean age of the respondents was 28.51 years $(S D=4.77)$, with a range from 20 to 46 years. The respondents identified themselves as heterosexual (72.8\%), bisexual (3.9\%), and (11.7\%) did not disclose their sexual orientation. In regards to marital status, the participants identified themselves as single (59.2\%), followed by married (26.2\%), domestic partnership (1.9\%), divorced (1.9\%), and (10.7\%) did not disclose their marital status. Overall, 77 participants resided in Kenya, two in the US, one in Germany, and one in Somalia. 
The participants were Kenyans residing in the US and Kenya, with an age minimum of 18 years. The choice of this age minimum was necessary because this is the age of sexual consent and majority in US and Kenya respectively. The two participants from Germany and Somalia were considered for this study because they indicated they had lived in Kenya for more than 15 years, so it is reasonable to infer they had adequate knowledge about HIV/AIDS campaigns in Kenya.

Participants residing in the US were only those who had spent more than three years in Kenya. This is because in such a period of time, they were acquainted with the HIV/AIDS problem in Kenya and the interventions used so far. The participants were recruited using email messages and social networking sites, such as Facebook and WhatsApp. These social sites have features that enable friends to interact and have private conversations that are secure and not visible to other unintended parties. Kenyans residing in the US have both WhatsApp and Facebook group accounts, thus it was easy to invite them to participate in the online survey through these platforms. The recruitment messages were posted in the social media sites inviting willing participants to take part in the survey, as well as refer the researcher to other potential participants. The recruitment email was also sent to Kenyans known to the researcher requesting them to pass the invitation to those interested in the survey. The study utilized snowball sampling, wherein the participants were asked to pass knowledge of the research on to other potential participants with similar demographic characteristics.

\section{Data Collection}

Data were collected using both open-ended and closed-ended survey questions on various aspects of the study, such as the role of culture on HIV/AIDS, government 
interventions, and HIV/AIDS campaigns in media. Surveys were suitable for this study because of their effectiveness in collecting data from a large sample and their convenience in study of perceptions and attitudes of people on issues affecting them (Allen, Titsworth, \& Hunt, 2009). Surveys also enable a researcher to ask standardized questions to all respondents (Croucher \& Cronn-Mills, 2015; Keyton, 2015).

\section{Measures}

$\mathrm{RQ}_{1}$ focused on the differences in knowledge portrayed by Kenyan men and women on the factors contributing to the high rate of infection and spread of HIV/AIDS in Kenya. This question was assessed using the HIV Knowledge Questionnaire (HIVKQ-18) (Carey \& Schroder, 2002). A previous study by Carey and Schroder (2002) using this scale found an alpha reliability of .88. The present study had an alpha reliability of .53. The reasons for this low reliability could be because the scale had nominal data (true, false, and I don't know) response options making it hard to calculate for reliability using SPSS. Also, the scale had not been used in Kenya before, so some cultural factors might have interfered with the validity of the scale. The scale had 18 brief statements assessing knowledge on transmission and control of HIV/AIDS that the respondents were supposed to read then answer either true, false, or I don't know. Some of the statements that the participants were asked to respond to were: There is a vaccine that can stop adults from getting HIV; people are likely to get HIV by deep kissing, putting their tongue in their partner's mouth, if their partner has HIV; a natural skin condom works better against HIV than does a latex condom; having sex with more than one partner can increase a person's chance of being infected with HIV. See the appendix for the full survey instrument. 
$\mathrm{RQ}_{2}$ assessed perceptions and attitudes of Kenyans towards the effectiveness of various health interventions used in the war on HIV/AIDS in Kenya. This construct was assessed using Health Intervention Scale purposely designed by the researcher for this study based on health interventions discussed in the literature review. The scale had fivepoint Likert questions ranging from strongly disagree to strongly agree. Respondents were asked to respond to brief statements assessing the effectiveness of eight health interventions: Male circumcision, use of condoms, women empowerment, education, and stringent laws and policies then respond based on the options on the Likert scale.

$\mathrm{H}_{2}$ assessed people’s attitudes towards media and government information on HIV/AIDS. Respondents were asked to respond to a closed-ended Likert-type scale assessing perceptions on credibility and effectiveness of information on HIV/AIDS from media and government sources. Specifically, the participants were asked how often they relied on newspapers, television, Internet, friends, and government offices for HIV/AIDS information.

$\mathrm{RQ}_{3}$ assessed attitudes of Kenyans towards people living with HIV/AIDS. The measure for this question was the Attitudes towards HIV Patients Scale (USAID, 2005). The scale adopted variables used by USAID to conduct a study on people's perceptions of people living with HIV/AIDS in Tanzania, and was adopted for this study, because of the closeness in demographics between Kenya and Tanzania. The previous study did not report the reliability of this scale. In the present study, the scale was modified to enhance readability. Thus, the scale had open and closed-ended questions and instead of presenting the items in one scale, the responses were treated as discrete statements. As a result of this modification the reliability of this scale was, therefore, not calculated. 
Respondents were asked to answer six questions touching on their relationship with HIV/AIDS-positive people. Some of the questions that the respondents were asked to respond to were: In a market of several vendors, would you buy food from a person living with HIV/AIDS or suspected of having HIV/AIDS; in your household, would you share utensils with a person living with HIV/AIDS or a person suspected of having HIV/AIDS; would you buy fresh vegetables from a shopkeeper or vendor if you knew that this person has the AIDS virus; if a relative of yours is infected with HIV/AIDS, would you be willing to care for her/him in the household; If a male teacher has the AIDS virus, but is not sick, should he continue teaching at the school, and if a female teacher has the AIDS virus, but is not sick, should she continue teaching at the school. In all of these questions, the respondents were required to answer yes, no, or I don't know. Whenever, they clicked no, they were directed to a link, where they were asked to explain the reasons for their response.

$\mathrm{RQ}_{4 \mathrm{a}}$ focused on the perceptions of Kenyans toward involvement of opinion leaders in HIV/AIDS campaigns. The respondents were asked the effects of involving religious leaders, politicians, community elders, and traditional healers in HIV/AIDS campaigns. The participants were required to select from the following options: A very negative effect, a mildly negative effect, I don't know, a mildly positive effect, and a very positive effect. Descriptive statistics were used to address this question.

$\mathrm{RQ}_{4 \mathrm{~b}}$ assessed how often Kenyans share HIV/AIDS information. To help answer this question, participants were asked how often they shared HIV/AIDS information with friends, family, colleagues, or acquaintances. The question was assessed using a Likerttype scale with the following response options: Not at all, rarely, sometime, often, and 
always. Descriptive statistics were then performed to help answer this question. The scale was designed by the researcher specifically for this study and was pilot tested before the deployment of the survey. The scale had a reliability of .84 .

$\mathrm{RQ}_{5}$ examined the perceptions of Kenyans toward government efforts in HIV/AIDS control in Kenya, and was assessed using an open-ended question, which asked the participants if, in their opinion, the government of Kenya had done enough to contain HIV/AIDS and explain the reasons behind their answers. The researcher involved two graduate research assistants to help with the coding of the data from the open-ended questions.

\section{Procedures}

The researcher sought permission from the Institutional Review Board (IRB) before conducting the study. The survey questionnaires were pretested using a small sample $(n=15)$ of international students at the researcher's university. The pilot study helped to unearth ambiguity in some of the questions and they were modified to ensure clarity before the deployment of the survey. This helped to ensure reliability and validity of the research instruments before deployment to collect data from the target sample.

Respondents were required to $\log$ on to the Internet at a place of their own convenience to take the survey through a link that was sent via the recruiting email. The survey was administered through Select Survey software, a package to which the researcher's university subscribes. Select Survey allows encryption of data and anonymous submission of surveys, by not collecting IP addresses or other information that can later be traced back to the participants. The researcher selected settings in the software package to analyze aggregated data only and not data from specific participants. 
Thus, this website was secure and did not violate participants' privacy. Participants were also required to give an informed consent before taking the survey.

\section{Data Analysis}

Data were analyzed using both quantitative and qualitative techniques. SPSS software was used to analyze quantitative data. Descriptive statistics helped to organize the data, thus enabling drawing of inference for research questions one, two, three, four (a), four (b), and hypothesis two. Croucher and Cronn-Mills (2015) argue that descriptive statistics help the researcher to visualize how data appear in numerical and visual terms, enabling him/her to have an insight into the underlying characteristics.

Regression analysis, using pairwise deletion of missing data, was performed to test hypothesis one, which suggested that age does not predict the knowledge of HIV/AIDS infection and spread among Kenyans. An independent samples t-test was also performed to screen if there were any differences in the attitudes depicted by men and women towards people living with HIV/AIDS.

Part of research question three and research question five were assessed using qualitative data, which were analyzed using thematic analysis because it allows for flexibility in data analysis. Braun and Clarke (2006) defined thematic analysis "as a way of analyzing and reporting patterns with in data” (p. 79). Themes were determined by the extent to which words or phrases captured issues pertinent to the research questions and represented emerging patterns (Lindlof \& Taylor, 2011). The researcher used unitizing to inductively analyze and break answers from the surveys into idea units depending on emerging themes (Lincoln \& Guba, 1985). Braun and Clarke (2006) defined inductive analysis as a data-driven way of coding data without trying to classify them into pre- 
existing categories or preconceptions. The units were then developed into categories depending with the similarities in the units as these related to the ideas sought in the research questions.

From the 103 responses from the participants, two coders selected the first 20 participants or $19.4 \%$ of the data, to test the applicability and practicality of the categories. Each coder reviewed the data and identified specific idea units. Based on Guetzkow’s U, coders had an intercoder unitizing reliability of .97 (Guetzkow, 1950).

The coders then developed emerging themes and placed the idea units into respective categories. Upon completion of the data analysis, the coders identified areas of disagreement, and established coding rules. The emerging disagreements from categorizing were resolved through consensus, where the coders mutually agreed where to place the disputed units. The coders came up with two categories: fear of infection and stigma.

Because research question five asked the respondents if in their opinion the government was committed in the war on HIV/AIDS and to explain their responses, there were opposing answers to this question, with some participants reporting the government was active in the war on HIV/AIDS and others disputing this position, the responses were treated separately. Some of the categories that the researchers came up with were: Free medical services provided by the government, adequate budgetary allocation, inadequate resources, corruption, lack of coordination, diversion of attention to other diseases, inadequate awareness, and frequent strikes by health workers. The results for this question and the categorizing reliability are presented in depth in the succeeding chapter. 


\section{Conclusion}

This chapter presented the methods, sampling procedure, sample, measures, and data analysis. This gives the framework of how the study was conducted and how inferences from the results were drawn. The next chapter presents both the quantitative and qualitative results from this study in depth. 


\section{CHAPTER IV}

\section{RESULTS}

The previous chapter explained the procedure for collecting and analyzing data. This chapter presents the results of the study. First, the quantitative results are presented, then the qualitative results. Some of the statistical analysis performed were descriptive statistics, independent samples $t$-test, and simple linear regression. Through these analyses, the chapter addresses the research questions and hypotheses suggested in this thesis. The results presented in this chapter give insights into the HIV/AIDS knowledge, attitudes towards people living with HIV/AIDS, perceptions of government and community opinion leaders’ involvement in HIV/AIDS campaigns, as well how HIV/AIDS information is shared among Kenyans.

\section{HIV/AIDS Knowledge}

HIV/AIDS control is influenced by the knowledge of the target population.

Therefore, research question one examined the knowledge portrayed by Kenyans towards factors contributing to infection and spread of HIV/AIDS. Descriptive statistics using the data gathered from the HIV/AIDS Knowledge Questionnaire (Carey \& Schroder, 2002) addressed $\mathrm{RQ}_{1}$.

The results revealed that the respondents had high knowledge on most of the aspects of HIV/AIDS infection and control. Some of the most notable results in which participants portrayed high knowledge were: HIV positive women do not necessary have babies with AIDS, people who are infected with HIV/AIDS do not quickly show signs, 
taking antibiotics does not prevent one from HIV/AIDS, and having sex with multiple partners increases the chances of HIV/AIDS infection.

The participants portrayed little knowledge in the following areas: One cannot get HIV by deep kissing if their partner has HIV, a female condom cannot decrease a woman's chance of getting HIV, there is no vaccine that can prevent adults from getting HIV, a natural skin condom cannot protect one from HIV, taking a test for HIV one week after having sex cannot reveal if one has HIV, and a person can get HIV from oral sex.

To assess whether there were any significant differences in the level of knowledge portrayed by men and women, an independent samples $t$-test, was performed between the responses given by men and women. The independent samples $t$-test revealed no significant differences in the level of knowledge portrayed by men $(M=43.9, S D=2.82)$ and women $(M=43.8, S D=2.03), t(80)=.06, p=.85$. The researcher also screened whether marital status determines the level of HIV/AIDS knowledge by conducting an independent samples $t$-test between the responses given by single and married respondents. The independent samples $t$-test revealed no significant differences in the level of knowledge portrayed by single participants $(M=43.76, S D=2.69)$ and married respondents $(M=44.16, S D=2.37), t(78)=.42, p=.53$. The screening for gender and marital status were necessary so as to assess if there is any need of tailoring HIV/AIDS messages to the target audience based on their gender and marital status. Definitely, these results indicate the areas that current and future HIV/AIDS campaigns in Kenya should address. These findings are analyzed in detail and inferences drawn in the succeeding discussion chapter. Table 1 below summarizes the findings from the descriptive statistics and scoring for each of the item of the HIV/AIDS Knowledge Scale. 
Table 1

HIV/AIDS Knowledge Portrayed by Kenyans

\begin{tabular}{|c|c|c|c|c|}
\hline Item & $M$ & $S D$ & $\%$ & $\bar{N}$ \\
\hline Coughing and sneezing do not spread HIV. & 2.88 & .46 & 92.8 & $\begin{array}{l}9 \\
7\end{array}$ \\
\hline $\begin{array}{l}\text { A person can get HIV by sharing a glass of water with someone } \\
\text { who has HIV. }\end{array}$ & 2.89 & .43 & 93.7 & $\begin{array}{l}9 \\
5\end{array}$ \\
\hline $\begin{array}{l}\text { Pulling out the penis before a man climaxes/cums keeps a woman } \\
\text { from getting HIV during sex. }\end{array}$ & 2.76 & .56 & 82.3 & $\begin{array}{l}9 \\
6\end{array}$ \\
\hline A woman can get HIV if she has anal sex with a man. & 2.70 & .63 & 79.4 & $\begin{array}{l}9 \\
7\end{array}$ \\
\hline $\begin{array}{l}\text { Showering, or washing one’s genitals/private parts, after sex } \\
\text { keeps a person from getting HIV }\end{array}$ & 2.92 & .31 & 92.8 & $\begin{array}{l}9 \\
7\end{array}$ \\
\hline $\begin{array}{l}\text { All pregnant women infected with HIV will have babies born } \\
\text { with AIDS. }\end{array}$ & 2.95 & .30 & 96.9 & $\begin{array}{l}9 \\
8\end{array}$ \\
\hline $\begin{array}{l}\text { People who have been infected with HIV quickly show serious } \\
\text { signs of infection. }\end{array}$ & 2.96 & .25 & 96.9 & $\begin{array}{l}9 \\
8\end{array}$ \\
\hline There is a vaccine that can stop adults from getting HIV. & 2.57 & .68 & 64.6 & $\begin{array}{l}9 \\
6\end{array}$ \\
\hline $\begin{array}{l}\text { People are likely to get HIV by deep kissing, putting their tongue } \\
\text { in their partner's mouth, if their partner has HIV. }\end{array}$ & 1.79 & .95 & 36.1 & $\begin{array}{l}9 \\
7\end{array}$ \\
\hline A woman cannot get HIV if she has sex during her period. & 2.95 & .26 & 95.9 & $\begin{array}{l}9 \\
8\end{array}$ \\
\hline $\begin{array}{l}\text { There is a female condom that can help decrease a woman's } \\
\text { chance of getting HIV. }\end{array}$ & 2.62 & .73 & 76.5 & $\begin{array}{l}9 \\
8\end{array}$ \\
\hline $\begin{array}{l}\text { A natural skin condom works better against HIV than does a latex } \\
\text { condom. }\end{array}$ & 2.35 & .56 & 38.8 & $\begin{array}{l}9 \\
8\end{array}$ \\
\hline A person will not get HIV if she or he is taking antibiotics. & 2.91 & .32 & 91.8 & 9 \\
\hline $\begin{array}{l}\text { Having sex with more than one partner can increase a person's } \\
\text { chance of being infected with HIV. }\end{array}$ & 2.95 & .30 & 96.9 & $\begin{array}{l}9 \\
7\end{array}$ \\
\hline $\begin{array}{l}\text { Taking a test for HIV one week after having sex will tell a person } \\
\text { if she or he has HIV. }\end{array}$ & 2.64 & .68 & 75.3 & $\begin{array}{l}9 \\
7\end{array}$ \\
\hline $\begin{array}{l}\text { A person can get HIV by sitting in a hot tub or a swimming pool } \\
\text { with a person who has HIV. }\end{array}$ & 2.81 & .51 & 86.6 & $\begin{array}{l}9 \\
7\end{array}$ \\
\hline A person can get HIV from oral sex. & 2.59 & .70 & 71.1 & $\begin{array}{l}9 \\
7\end{array}$ \\
\hline $\begin{array}{l}\text { Using Vaseline or baby oil with condoms lowers the chance of } \\
\text { getting HIV. }\end{array}$ & 2.73 & .55 & 94.2 & $\begin{array}{l}9 \\
7\end{array}$ \\
\hline
\end{tabular}


Note: The higher the frequency, the higher the HIV/AIDS knowledge portrayed by the respondents.

Hypothesis one predicted that age does not influence the level of knowledge on HIV/AIDS among Kenyans. To test this hypothesis, a simple linear regression was performed between the dependent variable (knowledge of participants toward HIV/AIDS) and independent variable (age of the participants). Missing cases were excluded pairwise, because of the small sample of the respondents. The regression results revealed no significant relationship existed between age and knowledge portrayed by respondents $R^{2}$ adj $=-.012, F(1,82)=.002, p=.98$. Age is therefore not a significant predictor of HIV/AIDS knowledge. Hypothesis one was thus supported.

\section{Perceptions of the Efficacy of Health Communication Interventions}

Research question two focused on the perceptions of Kenyans towards the effectiveness of various health communication interventions used in the control of HIV/AIDS in Kenya. All the items in this scale were considered separately, since each was developed from the interventions already identified in the literature review, and so the reliability of the scale was not calculated. Descriptive statistics were performed to help assess this research question.

The study established that the participants perceived the following strategies as the most effective: Promotion of education in society, involving community opinion leaders in the HIV/AIDS campaigns, faithfulness in sexual relationships, allocation of enough government resources in the war on HIV/AIDS, and use of condoms.

The study also found that the participants perceived the following interventions as the least effective: male circumcision, encouraging abstinence, and laws and policies. 
These results indicate the level of awareness and knowledge of Kenyans towards HIV/AIDS. They also compliment the results for research question one, and point out to areas that present and future interventions should address, if the war on HIV/AIDS is to be won. These results, as well as their, implications are discussed in the succeeding chapter. Table 2 below summarizes the descriptive statistics on HIV/AIDS interventions.

Table 2

HIV/AIDS Communication Interventions

\begin{tabular}{llll}
\hline Interventions & $M$ & $S D$ & $N$ \\
\hline $\begin{array}{l}\text { Promotion of male circumcision reduces the risk of HIV/AIDS } \\
\text { infection }\end{array}$ & 4.74 & 1.58 & 100 \\
$\begin{array}{l}\text { Involving community opinion leaders in HIV/AIDS campaigns } \\
\text { increases effectiveness of HIV/AIDS campaigns }\end{array}$ & 5.31 & 1.20 & 99 \\
$\begin{array}{l}\text { Promotion of education in society helps to control infection and } \\
\text { spread of HIV/AIDS. }\end{array}$ & 5.36 & 1.28 & 100 \\
$*$ *Promotion of condom usage is not effective in HIV/AIDS & 4.79 & 1.60 & 100 \\
$\begin{array}{l}\text { control. } \\
\begin{array}{l}\text { Government allocation of more budgetary resources for fighting } \\
\text { HIV/AIDS can prevent new infections and control the disease. }\end{array}\end{array}$ & 4.87 & 1.39 & 100 \\
$\begin{array}{l}\text { Laws and policies are effective in controlling HIV/AIDS. } \\
*\end{array}$ & 3.52 & 1.69 & 100 \\
$\begin{array}{l}* \text { Promotion of faithfulness in partners in sexual relationships is } \\
\text { not an effective method of controlling HIV/AIDS. }\end{array}$ & 4.92 & 1.72 & 101 \\
$\begin{array}{l}\text { Encouraging abstinence among unmarried people is an effective } \\
\text { way of controlling HIV/AIDS in Kenya. }\end{array}$ & 4.49 & 1.70 & 98 \\
\hline
\end{tabular}

Notes: The higher the mean, the more effective the intervention is perceived.

* Represents reverse coded items

\section{Attitudes Toward People Living with HIV/AIDS}

\section{Quantitative Data}

Research question three assessed the attitudes of Kenyans toward people living with HIV/AIDS. This question used closed-ended and open-ended questions. The 
reliability of the scale was not calculated, because the scale was modified to enhance readability for the participants; this in the judgement of the researcher might have interfered with the reliability of the scale. Besides, the scale had bipolar answer options such as yes (3), no (2), and I don't know (1), which made it difficult to calculate for reliability.

The descriptive analysis revealed that the participants had relatively positive attitudes toward people living with HIV/AIDS. In all of the responses, the highest score was three (3) indicating favorable attitude and the lowest one (1) indicating unfavorable attitude. Most of the participants indicated that they would care for their relatives infected with HIV/AIDS $(M=2.90, S D=.366)$, and that infected male teachers $(M=2.96, S D=$ $.283)$ and infected female teacher $(M=2.96, S D=.283)$ should continue teaching in schools. Some participants also indicated that they would share utensils with people living with HIV/AIDS $(M=2.85, S D=.461)$, give them a balanced diet $(M=2.62, S D=$ $1.00)$, and buy fresh vegetables from them $(M=2.81, S D=.366)$. The attitude towards people living with HIV were least favorable in some items such as buying food from people living with HIV/AIDS ( $M=1.29, S D=.470)$, giving HIV-positive people treatment and drugs $(M=2.45, \mathrm{SD}=1.17)$, compassion and support $(M=2.56, S D=$ 1.06), and counseling $(M=2.42, S D=1.19)$.

The researcher also examined if sex of participants had any influence on the attitudes toward people living with HIV/AIDS. Specifically, an independent $t$-test performed between the results from men and women revealed that there were no significant differences in the attitudes toward people living with HIV/AIDS portrayed by men $(M=14.43, S D=1.99)$ and women $(M=13.43, S D=2.51), t(12)=.661, p=.42$. 
There is, therefore, no relationship between the sex of the participants and the attitudes they hold toward people living with HIV/AIDS.

\section{Qualitative Data}

For all of the closed-ended questions in the Attitudes Towards HIV Patients' Scale (USAID, 2005), whenever the participants answered no to either buying food, sharing utensils, or buying fresh vegetables from people living with HIV/AIDS, they were directed to open-ended questions requesting them to explain their responses. Data from these questions were developed into two categories and analyzed qualitatively, depending with emerging patterns: fear of infection and stigma. The inter-rater reliability was calculated and Cohen’s Kappa $(K)=.87$ was reported (Cohen, 1960).

The fear of infection category contained words or phrases that indicated that the respondents would not help people living with HIV/AIDS because they were afraid of HIV/AIDS infection. Below are some of the excerpts from the participants when they were asked if they could either care or buy groceries from people living with HIV/AIDS:

Because of a case that was reported of a vegetable vendor who had HIV and used to inject himself then inject the tomatoes [with blood] he was selling, with the same syringe, with the intention of spreading the virus.

Because in my head, I will be thinking there is a possibility of being infected.

Some participants expressed fear that the handling of food stuff by a person living with HIV could put them at risk of infection. These comments show how the respondents feared buying food stuff from the vendors suspected of being infected with HIV/AIDS:

Depends with the hygiene displayed by the vendor's. If one is HIV positive and has TB, it can always be spread. 
I fear that the food he/she sells as he touches can be contaminated by the virus, if incase he has a wound or he/she gets a cut.

These comments show misconceptions and inadequate knowledge on how HIV/AIDS is transmitted. These comments also depict the people living with HIV/AIDS as unhygienic and capable of exposing other people to risk of infection by mere handling of food stuffs. The comments also reveal a hostile attitude towards people living with HIV/AIDS on flimsy grounds that are contrary to basic scientific knowledge of how HIV is transmitted from one person to another.

The stigma category had themes that suggested the participants would not help people suspected of living with HIV/AIDS because they feared associating with them because that is how the society depicts them. The category also contained the responses with explicit mention of stigma as the reason the respondents would not offer help to people living with HIV/AIDS:

I must confess it is due to a deeply entrenched stigma. I am educated, but I honestly just can't buy food stuffs from them. I question their hygiene as well, [but] I would however buy other products so as to promote them financially. The society paints them as a group that should be avoided. I just can't imagine buying food from one.

These comments suggest that, according to the respondents, the society portrays people living with HIV/AIDS as individuals who should be avoided and whom people should not associate with. This is the bluntest way in which stigma towards victims of HIV/AIDS is brought out. Some of the responses below also show the attitudes of the participants toward people living with HIV/AIDS: 
The fear of the unknown, I will not be comfortable.

Just out of fear or sometimes, I would pity them so much such that I want to avoid them.

These comments show that the participants perceived people living with HIV/AIDS as people who are different from the rest in the society and, hence, should be avoided for no apparent reason. This depicts prejudice to those with HIV/AIDS, as people in a free society are free to associate with others.

Based on the quantitative and qualitative data from this section, it is clear that stigma against people living with HIV/AIDS is still present in the Kenyan society. The results also indicate that people stereotype people living with HIV/AIDS as unhygienic and thus putting the lives of healthy members of the society at risk of infection if they associate with them. These findings will be discussed in depth in the succeeding chapter.

\section{Perceptions of Media Information on HIV/AIDS}

Hypothesis two predicted that media are the largest single source of AIDS information in Kenya, and most people perceive such information as more credible than information from government offices. Entertainment education is a key component of many HIV/AIDS campaigns broadcast via mass media. Therefore, before assessing $\mathrm{H}_{2}$, the researcher screened how the participants view EE by asking them to respond to a question examining their perceptions of the credibility of EE. The frequency count revealed that the question had mixed responses with the highest number of people $(M=$ $1.64, S D=1.028)$ answering they believed EE is somewhat credible (41.7\%), mildly credible (10.7\%), and very credible (27.2\%). Taken together, these answers show that the 
respondents have either limited knowledge on EE or just perceive it as less credible and, thus by extension, less effective when used in HIV/AIDS campaigns.

In regards to $\mathrm{H}_{2}$, descriptive statistics revealed that most people relied on the Internet for HIV/AIDS information $(M=4.04, S D=.98)$, followed by television $(M=$ $3.58, S D=.92)$, then friends $(M=3.15, S D=1.02)$, and lastly news $(M=3.10, S D=$ 1.06), but least on government sources $(M=2.61, S D=1.17)$. The results revealed that more people relied on the mass media (television and news) as compared to government sources, thus hypothesis two was supported. These results suggest that HIV/AIDS campaigns would reach a larger audience if entertainment education is used to communicate HIV/AIDS messages through the media and the Internet.

\section{Perceptions of Opinion Leaders}

Consistent with the DOI theory recognition of opinion leaders as important to the success of health campaigns, research question four (a) assessed the perceptions of Kenyans toward involvement of opinion leaders in HIV/AIDS campaigns. Specifically, the question assessed the participants’ perceptions of involving religious leaders, politicians, elders and traditional healers in the HIV/AIDS campaigns. This was necessary because DOI theory argues that involving trusted opinion leaders in health campaigns increases the chances of success and reduces the likelihood of boomerang effect, a situation in which the audience reject the messages. The opinion leaders identified above are respected in the Kenyan society and are relied on for guidance.

Table 3 below shows the results of the perceptions toward the involvement of religious leaders, politicians, community elders, and traditional or medicine men. The descriptive statistics revealed that the participants believed involving religious and 
community leaders would have a very positive effect in the outcome of the campaigns, while involving the politicians would have a mildly positive effect, but involving the traditional healers would have a mildly negative effect. From these results, it is evident that Kenyans perceive religious leaders and community elders as more credible in communicating about HIV/AIDS than politicians and traditional healers who are perceived as untrustworthy. The implications of these findings will be explored in-depth in the next chapter.

Table 3

The Effects of Involving Opinion Leaders in HIV/AIDS Campaigns

\begin{tabular}{llcc}
\hline Opinion Leaders & $M$ & $S D$ & $N$ \\
\hline Religious Leaders & 3.48 & .95 & 88 \\
Politicians & 2.63 & 1.18 & 88 \\
Community elders & 3.44 & .85 & 88 \\
Traditional healers/ Medicine men & 1.82 & 1.25 & 88 \\
\hline
\end{tabular}

Note: The higher the mean, the higher the credibility.

DOI theory also argues that social networks are important in the dissemination of information. To assess how often HIV/AIDS information is discussed in Kenya, research question four (b) asked the participants how often they share HIV/AIDS information with friends, family, colleagues, or acquaintances. Examining how people share HIV/AIDS information is important in helping to identify the social networks that can be utilized to communicate HIV/AIDS campaigns, so as reach a large audience and increase the chances of behavior change. The scale had a reliability of .84. Descriptive statistics were used to examine this research question. The results showed that people shared HIV/AIDS information more with friends and colleagues at work and least with family and 
acquaintances. This is an important finding because it can guide how present and future campaigns communicate HIV/AIDS messages. Specifically, the results suggest that using friends and workmates to communicate HIV/AIDS messages would ensure such information reach a larger audience. Table 4 below summarizes the findings on how HIV/AIDS information is shared.

Table 4

Sharing of HIV/AIDS Information

\begin{tabular}{llll}
\hline Social Networks & $M$ & $S D$ & $N$ \\
\hline Share with family & 2.81 & 1.25 & 89 \\
Share with friends & 3.26 & 1.13 & 89 \\
Share with colleagues at work & 2.87 & 1.11 & 89 \\
Share with acquaintances & 2.52 & 1.16 & 89 \\
\hline
\end{tabular}

Note: The higher the mean, the higher the information is shared with the respective group.

\section{Perceptions of Government's Role in HIV/AIDS Campaigns}

Research question five sought to examine the perceptions toward government efforts to mitigate HIV/AIDS in Kenya. Open-ended responses revealed mixed answers, with an almost equal number of participants taking opposing sides. The responses of the participants who said they had faith in the Kenyan government's commitment to tackle HIV/AIDS were treated separately from the ones of those who said they had no trust in the government's HIV/AIDS agenda. This led to creation of categories with distinct positive and negative content.

The responses of the participants who expressed confidence in the government's efforts to curb HIV/AIDS pandemic were developed into two categories depending on the 
themes, words, phrases or patterns that emerged: Free medical services provided by the government and adequate budgetary allocation. The units of analysis were themes and ideas from each sentence, hence in some instances, a sentence could have multiple ideas and themes. Through the rules developed during coding, a sufficient categorizing reliability was calculated and Cohen’s Kappa $(\mathrm{K})=.89$ was reported.

\section{Free Medical Services Provided by the Government}

This category had words or phrases that indicated the participants perceived the government to be committed in the HIV/AIDS war, because it offered free services such as provision of free condoms, ARTs, and VCT. The comments below show that the participants believed that provision of free testing, counselling and drugs as well as training of medics were indicators of the government's commitment in the war on HIV/AIDS. These comments also reveal that the government has, to some extent, created awareness about its HIV/AIDS programs, since the respondents can identify them:

By offering free medical services to people living with HIV/AIDS and free counseling services.

To my knowledge, the government provides medicine to patients, including free clinical tests and education on HIV care.

Provision of free counseling and testing services as well as the provision of free Antiretroviral drugs to the affected.

It has been providing drugs in the hospitals plus have trained doctors and nurses. These responses show that some of the respondents have confidence in the government's efforts to contain the spread of HIV/AIDS in Kenya, because of provision of free medical services. Although these services are freely provided by the government, 
it is surprising that the rates of infection still remain high. Compared to other categories, the "provision of free medical services category" gives insight into some of the activities that the Kenyan government is involved in an effort to control HIV/AIDS.

\section{Adequate Resource Allocation}

The second category of perception of government effort had comments that indicated the government had invested resources, either capital or human, in the war on HIV/AIDS. This category had comments such as educating personnel and funding HIV/AIDS research.

Some comments by the respondents show that they believed the government was supporting the combat of HIV/AIDS through funding of HIV/AIDS projects and enacting policies to deal with the scourge:

The government of Kenya has continuously supported the fight against HIV/AIDS financially and by way of policy. This is evident in annual increments in budgetary allocations towards the HIV/AIDS campaigns.

The government invests enough resources to combat HIV/AIDS. That's the reason the prevalence rates have significantly gone down. ARVs are also readily available to the patients suffering from the disease.

The respondents also reported that the Kenyan government efforts in addressing the HIV/AIDS scourge has led to drop in HIV/AIDS infection rates in Kenya. The comment below shows another response indicating the participants had confidence in government-led activities to control HIV/AIDS in Kenya: 
Decrease in the spread of HIV, thanks to government involvement, the Kenyan government invests enough to combat HIV/AIDS that is the reason the prevalence rates have significantly gone down.

The excerpts above show that, in the opinion of some Kenyans, the government has invested adequate resources towards HIV/AIDS campaigns. The war on HIV/AIDS is costly and requires immense resources. Although this category gives a glimpse of the respondents' perceptions on the activities of the Kenyan government in the HIV/AIDS war, these comments only give a general overview, but do not give any financial estimates or specific projects that are supported by the government.

Some of the participants, however, opined that the Kenyan government is not doing enough to mitigate the HIV/AIDS pandemic. From the responses of the participants who had no confidence in government efforts to curb HIV/AIDS, the following categories emerged: Inadequate resources, corruption, lack of coordination, diversion of attention to other diseases, inadequate awareness, and frequent strikes by health workers. The categories had a sufficient inter-rater reliability of Cohen's Kappa = .85 .

\section{Inadequate Resources}

This category had words and phrases that showed that some participants did not believe the government was doing enough to combat HIV/AIDS, because very little resources had been invested in the war on HIV/AIDS. Examples of excerpts in this category include:

Apart from issuing ARVs to people living with HIV/AIDS, we do not see massive anti-AIDS campaigns and awareness education being done to the public. 
Some facilities lack most equipment, and also there is a challenge of lack of enough skilled personnel.

[For] example, most of VCT centers are make-shift tents, whereas there are unused structures worth billions being erected everywhere by the government. These comments contradict those given by the respondents who expressed trust in the activities of the Kenyan government. However, it is difficult to substantiate the validity of these claims, since they are general and not supported by any specific facts.

\section{Corruption}

This category had words that showed participants felt that the resources meant for HIV/AIDS projects were embezzled by corrupt government employees, thus the intended projects never materialize. According to the respondents, this was a clear indication that the Kenyan government was not committed to fight HIV/AIDS. Examples in this category include the following:

More of its [government] resources are only squandered by few and nothing gets down to help the many HIV victims.

[The] government is so corrupt, hence [they] use the money meant for HIV/AIDS control for other purposes.

These statements show that a section of the participants believe that the resources meant for HIV/AIDS are misappropriated by unscrupulous government employees. This is an interesting finding, since very few extant research studies have explored how corruption impacts healthcare. This category was unique, in that it shows that those entrusted to run HIV/AIDS projects can impede the success of such programs if they allow corrupt practices and swindle public resources. 


\section{Diversion of Attention to Other Diseases}

Some participants reported that the attention on the HIV/AIDS war had shifted to other diseases such as cancer and diabetes. Thus, in their opinion, less was being done to curb HIV/AIDS, as control of other diseases was given prominence:

The emergence of new killer diseases like, cancer, have led to the neglect of HIV/AIDS menace.

This comment shows that some Kenyans feel that the government had diverted its focus to emerging diseases, thus slowing down the momentum on HIV/AIDS war. The comment also shows that the participants think the government's efforts to curb other diseases result in reduction of resources allocated to fight HIV/AIDS. However, the participants did not show any proof that the government was not addressing all these diseases simultaneously. This opinion is, therefore, subjective and mere speculation.

\section{Inadequate Awareness}

This category had words had phrases that revealed some participants believed the government had not done enough to create HIV/AIDS awareness, especially in the rural areas. Generally, the rural areas of Kenya tend to be less developed, and information flow is also slow compared to the urban areas. The comments below indicate that some participants feel the government had done little to educate communities on HIV/AIDS and create access to ARVs:

A lot of rural areas still lack awareness about HIV/AIDS, therefore they don't know the proper control measures.

We still have some communities in Kenya that don't have any access to ARVS and condoms. 
These responses compliment the findings on the attitudes towards people living with HIV/AIDS and Kenyans' knowledge on HIV/AIDS, that indicate there exists knowledge gaps in how the pandemic is spread and ways of in which it can be controlled. Creation of awareness, though not solely a responsibility of the government, can determine the success or failure of HIV/AIDS programs. Generally, these comments contradict those of the participants who indicated that the government had invested enough resources in the war on HIV/AIDS.

\section{Frequent Strikes by Health Workers}

This category had mention of industrial strikes by the medical professionals, that the participants felt had an impact on the health of people living with HIV/AIDS. The failure of the Kenyan government to address these strikes effectively led some participants to think the government was not doing enough to care for those living with HIV/AIDS. Example of responses in this category include:

Because often the health workers down their tools demanding for increased salaries. These health workers involve care givers of HIV/AIDS patients.

This category had the least themes and words, and suggests that the strikes of care providers can paralyze HIV/AIDS campaigns. This category is closely related to the category on inadequate resources, since industrial strikes often lead to shortage of human capital. Just like in the categories above, these claims by the respondents cannot be verified; any conclusions must thus remain general and cursory. 


\section{Conclusion}

This chapter has presented the results collected from the survey, and the next chapter discusses these results in depth and explains their implications to research and health communication. Taken together, these findings suggest a number of things. First, the results indicate that Kenyans have some knowledge of how HIV/AIDS is spread and can be controlled. Second, the results also reveal that age and sex do not predict HIV/AIDS knowledge and attitudes respectively. Also, the findings support various aspects of DOI that may be used to advance the HIV/AIDS war in Kenya. Lastly, the

results also indicate that Kenyans have opposing views about their government's efforts to curb HIV/AIDS. These results will be discussed in detail in the succeeding chapter. 


\section{CHAPTER V \\ DISCUSSION}

HIV/AIDS remains a global health challenge with adverse effects, especially in developing countries. This thesis, starts by reviewing the factors causing HIV/AIDS, methods of controlling HIV/AIDS, effects of HIV/AIDS, entertainment education, millennium development goals, and HIV/AIDS messages. The previous chapter presented the quantitative and qualitative results obtained from this study. The current chapter will summarize these findings, address the strengths and limitations of the study, identify theoretical implications for HIV/AIDS campaigns, and give suggestions for future research.

\section{Summary of Findings}

\section{Quantitative Analysis}

The study focused on the knowledge of participants toward infection and spread of HIV/AIDS, attitudes toward people living with HIV/AIDS, perceptions of the efficacy of various HIV/AIDS interventions, perceptions of Kenyans towards involvement of opinion leaders in campaigns, sharing of HIV/AIDS information, and sources of HIV/AIDS information. Consistent with the research questions, the hypotheses predicted that media would be the largest sources of information, and their information are perceived as credible compared to government sources, and that age does not predict the level of knowledge of the participants toward HIV/AIDS infection and spread. The post 
hoc hypotheses assessed whether sex determines the attitudes towards people living with HIV/AIDS and HIV/AIDS knowledge among Kenyans. The results clearly addressed the research questions and supported the hypotheses of the study.

Although the results suggest that the participants have high knowledge on how HIV/AIDS infection occurs, they also indicate that the participants have minimal knowledge on other issues related to the pandemic. For instance, the results suggest that the participants have little knowledge in aspects such as people being likely to get HIV/AIDS from kissing, oral sex, natural skin condom, and female condom. The results indicate the need for more campaigns to create more awareness. However, part of the reasons for these findings is because some sexual practices such as oral sex are not socially acceptable in Kenya and are viewed as moral perversions. Singhal and Rogers (2003) observed that, compared to men, women are least empowered to negotiate for safe sex. Therefore, it is possible that one of the reasons the participants portrayed low knowledge concerning female condoms is because they do not perceive women as capable of persuading their male sexual partners on what sex protection to use during sex, because men are in control of the sexual encounters.

The findings of the study also showed that sex and age did not determine the level of knowledge on HIV/AIDS and attitudes toward people living with HIV/AIDS. This is an important finding, since it suggests that Kenyans above the age of 18 and of either sex can learn about HIV/AIDS infection and ways of controlling it. This also suggests that HIV/AIDS campaigns can be designed to target all members of the society, without having to customize them to fit into any particular age or sex groups. One possible reason for this revelation could be because all the participants were 18 years and above, 
and therefore know the effects of HIV/AIDS and ways of protecting themselves from infection. However, this study utilized a small sample, and it is therefore possible that with a larger sample, age might predict the HIV/AIDS knowledge and the attitudes toward people living with HIV/AIDS.

Surprisingly, the results reveal that Kenyans do not perceive male circumcision, government allocation of resources, and laws and policies as effective in preventing HIV infection. These findings contradict previous research that identified these interventions as effective. For example, Mwandi et al. (2012) observed that male circumcision has been scientifically proven as effective in offering protection against HIV/AIDS and other STIs in unprotected sexual intercourse. Also, Gruskin et al. (2013) argue that laws and policies can help to protect people living with HIV/AIDS against discrimination in the society. However, it is not unusual that the participants do not perceive abstinence as an effective intervention since previous studies in Trinidad and Tobago, reveal that HIV/AIDS campaigns premised solely on abstinence do not achieve much success in influencing behavior change (Singhal \& Rogers, 2003).

Previous research has shown that people living with HIV/AIDS are stigmatized as sexually immoral, despite the fact that some may not have been infected with HIV/AIDS as a result of engaging in sexual activities (Singhal \& Rogers, 2003; Wilson, 2012). Although the present study reveals that the participants have favorable attitude toward people living with HIV/AIDS in aspects, such as allowing infected male and female teachers to continue teaching, sharing utensils with people living with HIV/AIDS, and caring for sick relatives, the participants show unfavorable attitudes towards activities, such as buying fresh vegetables from the people with HIV/AIDS, giving them treatment 
and drugs, offering compassion, counseling, and social support. Therefore, there is need for creation of more awareness and for campaigns to address stigma associated with HIV/AIDS.

Although the results revealed that the participants portray unfavorable attitudes toward people living with HIV/AIDS because of the fear of HIV infection in the process of caring for the people living with HIV/AIDS, there are other possible reasons why participants may depict unfavorable attitudes. First, HIV/AIDS is still a stigmatized disease (Singhal \& Rogers, 2003; Yuh et al., 2014). Therefore, even though the participants would like to be accommodative toward people living with HIV/AIDS, their socialization in the society may prompt isolationist attitude so as to prevent being ostracized by other members of the society for caring for people, who in the opinion of the society are "outcasts." Secondly, in the eyes of a prejudiced society, some of the activities that elicited negative attitudes, such as buying fresh vegetables and administering drugs and treatment, bring people into close proximity with people considered as pariahs because they contracted the HIV out of sex that many consider irresponsible. If this is the case, people may believe that, since the people living with HIV/AIDS could, therefore, have avoided the disease by being responsible, they should bear the brunt of the disease on their own, without inconveniencing so called responsible people.

The results also suggest that Kenyans rely more on the Internet, friends, television, and news, and least on government for HIV/AIDS information. They also perceive the HIV/AIDS information found in the news as more credible than that provided by the government. Considering the pivotal role played by the government in 
the war on HIV/AIDS in Kenya, there is need for the government to become more active in HIV/AIDS campaigns as a way of winning public trust. The implication of these findings are discussed in depth under theoretical implications.

The findings also reveal that Kenyans have confidence in the involvement of opinion leaders, such as religious leaders, and community leaders in HIV/AIDS campaigns. The participants have least trust in the involvement of politicians and traditional healers. The study also found that people share HIV/AIDS information more with friends, colleagues at work, and family. These findings are discussed in depth under the theoretical implications.

\section{Qualitative Analysis}

Research question three assessed the attitudes of Kenyans toward people living with HIV/AIDS. The qualitative data reveal that, although not very prevalent, AIDS is still a stigmatized disease. Some of the respondents indicated that they would not share utensils, care for people living with HIV/AIDS, or buy vegetables from them because of fear of infection, and stigma associated with HIV/AIDS. There is, therefore, a need for more awareness on how HIV is transmitted, to debunk the myths and misinformation that breed stigma and mistrust towards people with HIV/AIDS.

Research question five examined the perceptions of Kenyans toward government involvement in the HIV/AIDS war. Although the results from this section are conflicting, with some people applauding the government's efforts and others chiding it for poor performance, they indicate that the Kenyan government needs to get more involved in the war on HIV/AIDS. Based on the findings of the current study, some of the participants believe that the government is actively involved in providing free condoms, voluntary 
testing and counseling, collaborating with NGOs in HIV/AIDS projects, and creating awareness on HIV/AIDS. The results also show that some respondents do not view the efforts by the Kenyan government as effective in addressing HIV/AIDS, because of corruption that has led to embezzlement of funds meant for HIV/AIDS control programs, and diversion of attention to other diseases, such as cancer and diabetes. Although these diseases are claiming a lot of lives in Kenya every year, there is need for the government to remain focused on controlling the HIV/AIDS pandemic that continue to threaten both the social and economic development of Kenya, while at the same time researching and addressing other emerging diseases. Diversion of attention may lead to loss of track and of gains already realized.

\section{Implications}

\section{Theoretical Implications}

Taken together, the quantitative and qualitative results indicate that the war on HIV/AIDS is not lost, though there is still room for improvement. It is clear that much remains to be done, especially in addressing new infections and attitudes towards people living with HIV/AIDS. The results also suggest that there is need for more HIV/AIDS awareness campaigns to prevent new infections and protect the people living with HIV/AIDS from stigmatization. The formulation of the sustained development goals to replace millennium development goals that expired in 2015, heralds optimism in the war on HIV/AIDS. Specifically, this study indicates the areas that present and future HIV/AIDS campaigns should address under-sustained development goals, if the HIV/AIDS pandemic is to be controlled. 
Diffusion of innovations theory argues that involvement of opinion leaders in campaigns reduces the likelihood of the campaigns being rejected by the target audience (Barker, 2004; Rogers, 1998; Singhal \& Rogers, 2003). The results of this thesis suggest that the participants believe involving religious leaders and community elders would enhance the efficacy of the HIV/AIDS campaigns. Based on the literature review and results of the present study, therefore, there is a need for greater involvement of these stakeholders in the drafting and execution of HIV/AIDS campaigns and policies. However, although some of the participants had negative perceptions of the involvement of politicians in the war on HIV/AIDS, their role in legislation cannot be assumed. It is important that the politicians and health professionals build trust and formulate stringent laws and policies, that protect the people living with HIV/AIDS, to replace the current weak laws in existence. This will call for more consultation and partnership between the public, health professionals, and the government to ensure the laws address the concerns of the citizens.

Previous studies identify community engagement as an important tool in enhancing the success of health campaigns, because the target communities feel acknowledged and have a sense of ownership in the campaign initiatives (Muturi \& Mwangi, 2011; Patel, 2005). Opinion leaders such as religious leaders and community elders can be vital links between health professionals and the local communities in the fight on HIV/AIDS. Generally, these leaders are perceived as credible by the public because of their social status and duties that involve interacting with almost all members in the society. Thus, involving them in HIV/AIDS campaigns would increase the propensity of the audience to adopt the advocated health behaviors by the target 
communities, and encourage them to eschew risky sexual practices. This would

particularly be useful in the rural areas, where previous research indicates lack adequate HIV/AIDS awareness (Muturi \& Mwangi, 2011).

Some studies indicate that there is still some opposition from Christians and Muslims in Kenya concerning AIDS and preventive care, especially on some sexual commercials ran in the media (Nesidai et al., 2011; UNICEF, 2013). Encouraging dialogue between health professionals and religious leaders in Kenya would help change agents to alleviate these misunderstandings, leading to the design of HIV/AIDS messages that encourage behavior change, while at the same time observing sensitivity to religious beliefs of the public. Singhal and Rogers (2003) argue that many religions still perceive HIV/AIDS as a punishment from God for engaging in sexual immorality, and as such most HIV/AIDS campaigns ran by religious organizations emphasize abstinence. Involving the religious leaders, especially those who are well informed, would be important in helping to change the misconception that HIV/AIDS is a result of sexual immorality and encourage the adoption of other methods of controlling HIV/AIDS pandemic besides abstinence. The health professionals can achieve this by organizing workshops for the religious leaders and training them on HIV/AIDS infection, methods of control, and effects of HIV/AIDS pandemic in the society. The religious leaders who participate in these workshops can also be encouraged to share the knowledge and skills they acquire with their congregations. In this way, they become ambassadors for the prevention messages, breaking stigma about HIV/AIDS and encouraging more people to go for testing, counselling, or medication. This also goes a long way in mitigating stigma 
associated with HIV/AIDS by encouraging tolerance and accommodation towards people living with HIV/AIDS.

The diffusion of innovation is epitomized as a social process that occurs through interaction among members of the society. DOI theory postulates that social systems are pivotal in dissemination of innovations (Backer \& Rogers, 1998; Farr \& Ames, 2008). The perspectives of participants in this thesis support DOI in that; they believe that HIV/AIDS campaigns would be more pervasive if they appeal to friends, people at work, and family members, because this can increase the chances of sharing the information.

If the government and other development partners strategize new ways of fighting HIV/AIDS, it is possible to contain the pandemic by the 2030 deadline set under the sustainable development goals. In particular, there is need to shift the HIV/AIDS approach to align it to present communication innovations, such as the use of social media. Previous studies indicate that social media can be used in healthcare to educate the public about certain health issues and procedures such as treatment of various diseases (Moses, Chaitt, \& Jones, 2014). The alignment of health campaigns to ensure they resonate with modes mostly used by people will not only ensure the information reaches more people, but will also increase the chances of behavior change.

The advent of the social media has given rise to social platforms, through which friends and workmates can connect to discuss social issues. Social media sites such as Facebook, WhatsApp, and Twitter, therefore, can be used to run HIV/AIDS messages. For instance, having a Twitter hashtag when running a campaign and analyzing how the public are sharing and responding to the campaign can help to gauge the performance of the campaign. Social media channels enable the users to share the messages with their 
online friends, and this would be important in creating HIV/AIDS awareness. Another way of encouraging workmates to share HIV/AIDS messages would be conducting HIV/AIDS training in workplaces and encouraging the employees to role-play certain characters in the campaign. This would help them to retain the health information and increase their chances of talking about the campaign even after the training, thus creating more awareness. Another way of increasing sharing of HIV/AIDS messages would be running HIV/AIDS messages through mobile applications, where people can share the information with friends and family.

The results also found that people perceive the HIV/AIDS information in the Internet and media as more credible compared to government information. This suggests that HIV/AIDS campaigns can be more successful in creating awareness and shaping the attitudes of the target audiences if ran through the media or Internet. The recent data by Internet Live Stats (2016) indicate that Kenya has 45\% Internet penetration. This indicates the number of people who access Internet at home, workplace as well as any other device. Use of the Internet to run HIV/AIDS would, therefore, help the messages to reach a wider audience and, in turn, create more awareness. Since the participants expressed low opinion of the government's sources of HIV/AIDS information, the Kenyan government should consider complimenting its communication strategies by reaching out to media houses to run its HIV/AIDS campaigns. One possible suggestion in utilizing these sources would be to use entertainment education in the campaigns, because the results indicate that the participants perceive it as effective in influencing behavior change. 
Previous studies (e.g. Mahoney \& Bates, 2013; Singhal \& Rogers, 2003) argue that entertainment education is effective in imparting behavior and attitude change, especially when influential characters who the audience can identify with are used as characters in such campaigns. Since the present study shows that the participants believe involving trusted opinion leaders would lead to the success of HIV/AIDS campaigns, present and future campaigns should consider involving these opinion leaders in the design and execution of HIV/AIDS projects. Such opinion leaders can also be approached to endorse HIV/AIDS campaigns or be invited to discuss HIV/AIDS projects in the media as a way of creating more awareness of the importance of adopting preventative methods and abandon disruptive cultural practices that predispose them to infection.

Although previous research (e. g. Mwandi et al., 2012) shows that male circumcision helps to prevent HIV/AIDS and other STIs, the results of the present study show that the participants do not perceive it as effective in controlling the HIV/AIDS. Encouraging people to adopt condoms, sexual faithfulness, abstinence for those not yet married, and male circumcision would help in addressing HIV/AIDS. Further, the characters of these opinion leaders can be role played in HIV/AIDS messages. Beyond the scope of the present study, use of entertainment education would also help to address deceptive cultural beliefs and misinformation such as belief that sexual cleansing cannot spread HIV/AIDS and that having sex with a virgin can heal HIV/AIDS. Addressing these practices would help to inform the public of their danger, since they expose people to HIV/AIDS infection. Use of entertainment education in HIV/AIDS messages would 
also be helpful in encouraging health literacy and building societal capacity to deal with general health challenges.

The participants identified education as the most effective intervention in controlling HIV/AIDS. Previous studies identify education as crucial in shaping attitudes and creation of awareness about HIV/AIDS (Aggleton, Yankah, \& Crewe, 2011; Thanavanh et al., 2013). In particular, promotion of AIDS education would help to address stigma against people living with HIV/AIDS and enhance the society's knowledge about HIV/AIDS. Oluga et al. (2010) argue that the discussion of sexual topics in Tanzanian and Kenyan schools is seen as a taboo and immoral. Therefore, there is need for better integration of HIV/AIDS topics in the school curriculum and the encouragement of more open discussion on HIV/AIDS among learners and instructors so as to boost prevention and control programs. This would also encourage more people to go for testing and counselling, which is the first step in knowing one's HIV status. This will go a long way in shaping and changing attitudes about HIV/AIDS and create capacity for social support for those already infected. However, although education can help mitigate stigma and create more awareness, it is important to note that attitudes and behaviors take time to change; thus, there is need to use several strategies in HIV/AIDS campaigns and have long term goals that ensure the campaigns achieve their purpose.

This thesis indicates the areas that future HIV/AIDS research campaigns in Kenya should aim to accomplish. In general, with the deadline on millennium development goals having passed without the full control of the AIDS pandemic, it is important to reconsider the present strategies used to mitigate the pandemic. The results of the study suggest that the attitudes of Kenyans are favorable to new possibilities and that the 
citizenry are well informed about the pandemic, but more needs to be done to sustain the war on HIV/AIDS.

\section{Methodological Implications}

This study was carried out in Kenya, a country facing a significant threat of HIV/AIDS. The results, in some way, gauge the progress made in the war on HIV/AIDS, and give insights into the knowledge and attitudes of Kenyans toward certain aspects of HIV/AIDS. These results are, therefore, important in guiding how present and future HIV/AIDS campaigns should be conducted. Specifically, the findings of this study suggest that the campaigns in Kenya should aim at creating more awareness on HIV/AIDS, shaping the attitudes towards people living with HIV/AIDS, and identifying the most effective communication channels and social networks to transmit the HIV/AIDS messages in way that resonates well with the target audience.

Another strength of this study is the use of both qualitative and quantitative methods to analyze data. The more in-depth qualitative data were helpful in addressing the research questions and hypotheses of this thesis. This thesis also used a variety of scales that helped the researcher to collect rich data that were useful in revealing how Kenyans perceive certain elements of HIV/AIDS. Also, the use of open-ended questions in the collection of the data empowered the respondents to explain their thoughts on the HIV/AIDS situation in Kenya.

While the qualitative and quantitative methods used in this study give valuable insights into the HIV/AIDS situation in Kenya, one must consider some limitations in this thesis. The first limitation of this study concerns some of the scales used in this study. For instance, whereas previous studies using HIV/AIDS Questionnaire (Carey \& Schroder, 
2002) produced high reliability, the present study had very low reliability for this scale. One of the possible causes for the low reliability is because the scale had answer options such as True, false, and I don't know that made it difficult to calculate for reliability using SPSS software that was used to analyze data for this thesis. Also, some items in the scale, such as oral sex are considered inappropriate in the Kenyan culture. Therefore, it is possible that some cultural factors might have interfered with the validity of the scale.

Second, the snowball-sampling and the small sample used in this study limit the generalizability of the findings to the entire Kenyan population. Also, being an international study, several factors might have hindered willing Kenyans from participating. The study, for instance, was conducted using social networks, and not many Kenyans use these platforms. Internet connectivity could also have been a hindrance since not many people in Kenya, especially in the rural areas, have adequate access to the Internet. Online surveys are also not common in Kenya, as most of the researchers present hard copies of questionnaires and request the participants to return them on a specific date and location. Closely connected to this, is the fact that a large number of participants left many questions unanswered.

The final limitation of this study was the small number of the Kenyans in the US who took the survey compared to those in Kenya. Although one of the intentions of this study was to compare responses of the two groups, this was not possible owing to the large discrepancy in numbers between the two groups. Due to the small sample available, the researcher considered responses from two participants from Germany and Somalia because they had lived in Kenya for more than five years, so had enough knowledge of the HIV/AIDS situation in Kenya. 


\section{Implications for Future Research}

The current research resulted in several findings that have implications for future research in HIV/AIDS in Kenya. These findings, for instance, suggest that that age and sex are not indicators of knowledge and attitudes of HIV/AIDS. Thus, the first possible area for future research would be to explore the factors that influence knowledge and attitudes on HIV/AIDS in Kenya.

Most of the scales used in this study were borrowed from studies done outside Kenya. Although credible, the reliability of the scales could be improved by taking into account specific cultural factors in Kenya. The second possibility is, therefore, to develop HIV/AIDS scale specifically for Kenya, testing elements such as knowledge, attitudes, or perceptions of efficacy of interventions currently in use.

The majority of the participants in this study are probably literate people who are knowledgeable about HIV/AIDS infection. Another possible area for future research would be to conduct a similar study with people in the rural areas who have limited access to the Internet and computers, and who may not have participated in this study. Besides, most people in the rural areas in Kenya have lower literacy levels compared to those in the urban areas. Therefore, it is worth studying their HIV/AIDS knowledge and attitudes toward people living with HIV/AIDS.

Furthermore, the sample of this thesis were individuals who were either 18 or above in age, thus does not consider the views of those below this age bracket. HIV/AIDS is a deadly disease affecting people in all age brackets. Previous research study by Nesidai et al. (2010) in a Kenyan public university, for instance, found that the youth are aware that condoms are effective in preventing sexually transmitted infections, 
but do not feel susceptible to the disease, so they rarely use them. They also observed that the Kenyan youth engage in sex with multiple partners without using condoms. It is therefore important to study the HIV/AIDS knowledge and attitudes portrayed by adolescents in Kenya. Such a study would help to guide how HIV/AIDS campaigns targeting this group should be conducted.

In addition, the results revealed that many Kenyans do not perceive male circumcision and abstinence as effective methods of controlling HIV/AIDS. There is a need, therefore, for more research in this area. In particular, it would be interesting to study the perceptions of Kenyans toward the efficacy of male circumcision in controlling HIV/AIDS, and if it is carried out in a safe way that does not predispose the initiates to HIV/AIDS infection.

Another area worth studying in future is the motivation for sharing HIV/AIDS information. The results of the present study indicate that Kenyans share information with family, colleagues at work, and friends. It would be important to examine the reasons behind their motivation to share the information and the receptivity of this information by the audience.

Entertainment education is an important tool in the war on HIV/AIDS (Singhal \& Rogers, 2003). Although EE has been discussed in this study, it was not the primary focus of this thesis. It would, therefore, be an interesting area to explore in future. Specifically, future studies should explore the possibility of using entertainment education in HIV/AIDS campaigns in the social media. This would be important because the present study reveals that people share HIV/AIDS information more with friends, so it is possible that they also share information with people in their social networks. 
Finally, this study had a primary focus in Kenya. In future, it will be worth studying how people in other countries perceive HIV/AIDS, its effects, and methods of control. For instance, a comparison study between two countries, one with high literacy levels and another with low literacy levels would be ideal. This will act as a guide to help who people develop HIV/AIDS campaigns to know how to customize their campaigns in these different countries. It would also be a worthwhile study to compare the findings of this study to similar ones done in other countries so as to identify how people in different countries perceive HIV/AIDS and their knowledge and attitudes towards the pandemic.

\section{Conclusion}

Health communication is a broad field with many unexplored areas and this study only adds to what other scholars have done. The HIV/AIDS situation in Kenya remains a great threat, and it will remain so, unless stringent measures are taken to reverse the current trend. There is need for the government to rethink the strategies it has used so far in the war on HIV/AIDS and take stock of what has been achieved and devise ways of taking the war beyond the present confines.

As mentioned earlier, HIV/AIDS remains a global concern that requires a multifaceted approach. Although this study shows that Kenyans are knowledgeable about HIV/AIDS and that there are strategies in place to combat HIV/AIDS, the study also reveals that more needs to be done. HIV/AIDS has been around in Kenya since the 1980s, and it will require concerted efforts to eradicate. The ultimate control of HIV/AIDS remains investment in research and strengthening of the existing institutions.

The formulation of sustainable development goals by the global community at the close of the deadline of MDGs in 2015 rekindles the embers of the HIV/AIDS war and 
gives more hope of controlling the HIV/AIDS pandemic, since the scourge is still in the radar of world governments. The new sustainable development goals offer a broader scope, specific strategies, and timelines of dealing with diseases such as HIV/AIDS by 2030. Considering all the negative impacts of HIV/AIDS on the economic and social welfare in Kenya, the control of the scourge will be a quantum leap forward to the achievement of a more vibrant and prosperous nation. 


\section{REFERENCES}

Abate, T. D. (2008). Education towards liberation: HIV/AIDS and women in Sub-Sahara Africa. (Master's thesis). Available from ProQuest Dissertations and Theses Global (Order No. MR45747).

Ahmad, J. S. (2005). Push and pull factors in changing health behavior: A theoretical framework. In M. Haider (Ed.), Global public health communication. Challenges, perspectives, and strategies (pp. 39-58). Sudbury, MA: Jones and Bartlett.

Aggleton, P., Yankah, E., \& Crewe, M. (2011). Education and HIV/AIDS-30 years on. AIDS Education and Prevention, 23, 495- 507. doi: 10.1521/aeap.2011.23.6.495

Airhihenbuwa, C., \& Webster, J. (2012). Culture and African contexts of HIV/AIDS prevention, care, and support. Journal of Social Aspects of HIV/AIDS, 1, 4-13. doi: 10.1080/17290376.2004. 9724822

Allen, M., Titsworth, S., \& Hunt, S. K. (2009). Quantitative research in communication. Thousand Oaks, CA; Sage.

Ayikukwei, R., Ngare, D., Sidle, J., Ayuku, D., Baliddawa, J., \& Greene, J. (2008). HIV/AIDS and cultural practices in Western Kenya: The impact of sexual cleansing rituals on sexual behaviors. Culture, Health, and Sexuality, 10, 587-599. doi: 10.1080/13691050802012601

Backer, T. E., \& Rogers, E. M. (1998). Diffusion of innovations theory and work-site AIDS programs. Journal of Health Communication, 3, 17-28. doi: 1081-0730/98 
Barker, K. (2004). Diffusion of innovations. A world tour. Journal of Health Communication, 9, 131-137. doi: 10.1080/108107ss30490271584

Barnett, T., \& Whiteside, A. (2006). AIDS in the twenty first century: Disease and globalization (2nd ed.). New York, NY: Palgrave Macmillan.

Bekalu, M. A, \& Eggermont, S. (2014). The role of communication inequality in mediating the impacts of socioecological and economic disparities on HIV/AIDS knowledge and risk perception. International Journal for Equity in Health, 13, 214. doi: $10.1186 / 1475-9276-13-16$

Bernardi, R., \& Chiara, F. (2011). ICTs and monitoring of MDGs. A case of Kenya HIV/AIDS monitoring and evaluation in a donor multi-agency context. Information Technology for Development, 17, 24-41. doi: $10.1080 / 02681102.2010 .511699$

Boutayeb, A. (2009). The impact of HIV/AIDS on human development in African countries. BMC Public Health, 9, 1-10. doi: 10.1186/1471-2458-S1-S3

Braun, V., \& Clarke, V. (2006). Using thematic analysis in psychology. Qualitative Research in Psychology, 3, 77-101. doi: 10.1191/1478088706qp063oa

Campbell, C. (2010). Political will, traditional leaders and the fight against HIV/AIDS: A South African case study. AIDS Care, 22, 1637-1643. doi: 10.1080.0954121.2010.516343

Carey, M. P., \& Schroder, K. E. (2002). Development and psychometric evaluation of the brief HIV knowledge questionnaire (HIV-KQ-18). AIDS Education and Prevention, 14, 174-184. doi:10.1521/aeap.14.2.172.23902 
Chang, F., Prytherch, H., Nesbitt, R., \& Wilder-Smith, A. (2013). HIV related travel restrictions. Trends and country characteristics. Global Health Action, 6, 1-8. doi: 10.3402/gha.v6i0.20472

Cohen, J. (1960). A coefficient of agreement for nominal scales. Educational and Psychological Measurement, 20, 37-46. doi: 10.1177/001316446002000104

Chicoine, L. (2011). AIDS mortality and its effect on the labor market: Evidence from South Africa. Journal of Development Economics, 98, 256- 269. doi: 10.1016/j.jdeveco.2011.08.003

Croucher, S. M., \& Cronn-Mills, D. (2015). Understanding communication research methods: A theoretical and practical approach. New York, NY: Routledge.

D’ Angelo, P., Pollock, J. C., Kiernicki, K., \& Shaw, D. (2013). Framing of AIDS in Africa, press-state relations, HIV/AIDS news, and journalistic advocacy in four Sub-Saharan Anglophone newspapers. Politics and Life Sciences, 32, 100-125. doi: 10.2990/32_2_100

Dodd, R., \& Cassels, A. (2006). Health, development and millennium development goals. Annals of Tropical Medicine and Parasitology, 100, 379-387. doi: $10.1179 / 136485906 X 97471$

Easterly, W. (2008). How the millennium development goals are unfair to Africa. World Development, 37, 26-35. doi: 10.1016/j.worlddev.2008.02.009

Farr, A. C., \& Ames, N. (2008). Using diffusion of innovations theory to encourage the development of children's health collaborative. A formative evaluation. Journal of Health Communication, 13, 375- 388. doi: 10.1080/10810730802063835 
Fehlinga, M., Nelson, B. D., \& Venkatapuramd, S. (2013). Limitations of the millennium development Goals: A literature review. Global Public Health, 8, 1109-1122. doi. 10.1080/17441692.2013.845676

Frölich, M., \& Vazquez-Alvarez, R. (2009). HIV/AIDS knowledge and behavior: Have information campaigns reduced HIV infection? The case for Kenya. African Development Review, 21, 86- 146. doi: 10.1111/j.1467-8268.2009.00205.x

Gruskin, S., Safreed-Harmon, K., Ezer, T., Gathumbi, A., Cohen, J., \& Kameri-Mbote, P. (2013). Access to justice: Evaluating law, health, and human rights programs in Kenya. Journal of International Aids Society, 16, 1-7. doi:

10.7448/IAS.16.3.18726

Gnauck, K., Ruiz, J., Kellett, N., Sussman, A., Sullivan, M. A, Montoya, M., ... Mwanthi, M. A. (2013). Economic empowerment and AIDS related stigma in rural Kenya: A double-edged sword? Culture, Health, and Sexuality, 15, 851-865. doi: 10.1080/13691058.2013.789127

Guetzkow, H. (1950). Unitizing and categorizing problems in coding qualitative data. Journal of Clinical Psychology, 6, 47-58. Retrieved from http://dx.doi.org/10.1002/1097-4679(195001)6:1\%3C47::aidjclp2270060111\%3E3.0.co;2-i

Haider, M., Pal, R., \& Al-Shoura, S. (2005). Diffusion of innovations and foment: A synernergistic theoretical framework in health communication. In M. Haider (Ed.), Global public health communication. Challenges, perspectives, and strategies (pp. 1-24). Sudbury, MA: Jones and Bartlett. 
Hutchinson, P. L., Mahlalela, X., \& Yukich, J. (2007). Mass media, stigma, and disclosure of HIV test results: Multilevel analysis in the Eastern Cape, S. Africa. AIDS Education and Prevention, 19, 489-510. doi: 10.1521/aeap.2007.19.6.489

Internet Live Stats. (2016). Internet users in Kenya. Retrieved from http://www.Internetlivestats.com/Internet-users/kenya/

Joint United Nations Program on HIV/AIDS. (2014). Kenya AIDS response progress report. Retrieved fromwww.unaids.org/sites/ default/files/country/documents/KEN_narrative_2014.pdf

Keyton, J. (2014). Communication research: Asking questions, finding answers (4th ed.). New York, NY: McGraw-Hill.

Kreuter, M., Farrel, D., Olevitch, L., \& Brennan, L. (2000). Tailoring health messages. Customizing communication with computer technology. Mahwah, NJ: Lawrence Erlbaum Associates.

Langat, G., Falkingham, J., Madise, N., \& Evandrou, M. (2012). Concern about HIV and AIDS among older people in the slums of Nairobi, Kenya. Society for Risk Analysis, 32, 1512- 1523. doi: 10.1111/j.1539-6924.2011.01765.x

Lee, W. (2015). Culture and classification: An introduction to thinking about ethical issues of adopting global classification standards to local environments. Culture and Classification, 42, 302- 307. Retrieved from https://www.researchgate.net/

Lincoln, Y. S, \& Guba, E. G. (1985). Naturalistic inquiry. Beverly Hills, CA: Sage.

Lindlof, T. R, \& Taylor, B. C. (2011). Qualitative communication research methods (3rd ed.) Thousand Oaks, CA: Sage. 
Mahat, G., Scoloveno, M. A., \& Ayres, C. (2014). Comparison of adolescents’ HIV/AIDS knowledge and self-efficacy across two cultures. Journal of Cultural Diversity, 21, 152- 158. Retrieved from http://www.ncbi.nlm.nih.gov/ pubmed/ 25898500

Mahoney, M. L., \& Bates, B. L. (2013). The impacts of an entertainment-education radio serial drama in Botswana on outcomes related to HIV prevention goals in the president's emergency plan for AIDS relief. Journal of African Media Studies, 5, 353-367. doi: 10.1386/jams5.3.353_1

Moradi, G., Malekafzadi, H., Naieni, K., Rashidian, A., Vazirian, P., Mirzazadeh, A., \& Barat, H. (2011). HIV/AIDS situation in economic cooperation countries; achievement and gaps toward millennium development goals. Journal of Family and Reproductive Health, 5, 1-9. Retrieved from http://jfrh.tums.ac.ir/index.php /jfrh /article/view/114/114

Moses, R., Chaitt, M., \& Jones, D. (2014). Social media in healthcare: Lessons from the field. Journal of Health Care Compliance, 1, 17- 22. Retrieved from http://www.aspenpublishers.com

Muturi, N., \& Mwangi, S. (2011). Older adults’ perspectives on HIV/AIDS prevention for rural Kenya. Health Communication, 26, 712- 723. doi: $10.1080 / 10410236.2011 .563354$

Muthusamy, N., Levine, T., \& Weber, R. (2009). Scaring the already scared: Some problems with HIV/AIDS fear appeals in Namibia. Journal of Communication, 59, 317- 344. doi: 10.1111/j.1460-2466.2009.01418.x 
Mwandi, Z., Bunnel, R., Cherutich, P., Mermin, J., Kim, A. A., Gichangi, A.,...Kaiser, R. (2012). Male circumcision programs in Kenya: Lessons from the Kenya AIDS indicator survey 2007. Bull World Health Organ, 90, 642- 651. doi:

10.2471/BLT.11.096412

Nageta, J., Magerenge, R., Young, S., Oguta, J., Weiser, S., \& Cohen, C. (2012). Social determinants, lived experiences, and consequences of household food insecurity among persons living with HIV/AIDS on the shore of L. Victoria, Kenya. AIDS Care, 24, 728-736. doi: 10.1 080/9540121.2011.630358

National Aids Control Council of Kenya \& National AIDS and Sexually Transmitted Infections Control Program. (2012). The Kenya AIDS epidemic update 2012. Retrieved from http://www.unaids.org/sites/default/files/en/dataanalysis/knowyourresponse/count ryprogressreports/2013countries/ce_KE_Narrative_Report.pdf

National AIDS and Sexually Transmitted Infections Control Program. (2014). Kenya HIV Estimates. Retrieved from http://reliefweb.int/sites/reliefweb.int/files/resources/HIV\%20estimates\%20report \%20Kenya\%202014_print.pdf

National Council for Law Reporting. (2010). Constitution of Kenya. Retrieved from www.Kenyalaw.org 
Nesidai, K., Ng’ang’a, Z., Mwangi, M., \& Wanzala, P. (2011). Knowledge, attitude and practice factors associated with condom use among undergraduate students of a public university in Kenya: A case of Jomo Kenyatta University of Agriculture and Technology. African Journal of Health Science, 19, 41-52. Retrieved from http://www.ajhsjournal.or.ke/admin/current/hrFihEUhjQp.pdf

Ngula, K., \& Miller, N. (2010). Self-disclosure of HIV seropositivity in Kenya by HIVpositive Kamba men and their families. Southern Journal of Communication, 75, 328- 348. doi: 10.1080/1041794x.2010.50443

Njue, C., Nzioka, C., Ahlberg, B., Pertet, A., \& Voeten, H. (2009). “If you don’t abstain you will die of AIDS”: AIDS education in Kenyan public schools. AIDS

Education and Prevention, 21, 169-179. doi: 10.1521/aeap.2009.21.2.169

Oluga, M., Kiragu, S., Mohamed, M., \& Walli, S. (2010). Deceptive cultural practices that sabotage HIV/AIDS education in Tanzania and Kenya. Journal of Moral Education, 39, 365-380. doi: 10.1080/03057240.2010.497617

Okidu, O. (2013). A comparative study of two communication models in HIV/AIDS coverage in selected Nigerian newspapers. Global Health Action, 6, 1-10. doi: 10.3402/gha.v6i0.18993

Patel, D. S. (2005). Social mobilization as a tool for outreach programs in the HIV/AIDS crisis. In M. Haider (Ed.), Global public health communication. Challenges, perspectives, and strategies (pp. 91-102). Sudbury, MA: Jones and Bartlett.

Perloff, R. M. (2014). The dynamics of persuasion: Communication and attitudes in the $21^{\text {st }}$ century (5th ed.). New York, NY: Routledge. 
Qiao, X. (2011). Unsafe-sex, AIDS, and development. Journal of Economics, 105, 263279. doi: 10.1007/s00712-011-0230-z

Richman, K. S., Kakietek, J., Manteuffel, B. A., Rodriguez-Garcia, R., Bonnel, R., N’jie, N., ... Fruh, J. (2013). Evaluating the effects of community-based organization engagement on HIV and AIDS-related risk behavior in Kenya. AIDS Care, 25, 67-77. doi: 10.1080/09540121.2013.778383

Rogers, E. M. (2003). Diffusion of innovations (5th ed.). New York, NY: Free Press.

Rogers, E. M, Vaughan, P. W, Swalehe, R., Rao, N., Svenkerud, P., \& Sood, S. (1999). Effects of an entertainment-education radio soap opera on family planning behavior in Tanzania. Studies in Family Planning, 30, 193- 211. Retrieved from http:/www.jstor.org/stable/172196

Seth, P., Kidder, D., Pals, S., Parent, J., Mbatia, R., Chesang, K., ... Bachanas, P. (2013). Psychosocial functioning and depressive symptoms among HIV-positive persons receiving care and treatment in Kenya, Namibia, and Tanzania. Society for Prevention Research, 15, 318-328. doi: 10.1007/s11121-013-0420-8

Shimbuli, F., Oyedokun, C., \& McNally, A. (2009). The impact of the HIV/AIDS awareness campaign on knowledge, attitudes, beliefs, sexual behavior change, and confidence in sexual practices. Nawa Journal of Language and Communication, 3, 81-100. Retrieved from http://hdl.handle.net/10628/36

Sia, D., Onadja, Y., Nandi, A., Foro, A., \& Brewer, T. (2013). What lies behind gender inequalities in HIV/AIDS in Sub-Saharan African countries? Evidence from Kenya, Lesotho, and Tanzania. Health Policy and Planning, 29, 938-949. doi: 10.1093/heapol/czt075 
Singhal, A., \& Rogers, E. (2003). Combating AIDS: Communication strategies in action. New Delhi, India: Sage.

Taylor, R. (2013). The politics of securing borders and the identities of disease. Sociology of Health and Illness, 35, 241- 254. doi: 10.1111/467-9566.12009

Thanavanh, B., Harun-or-Rashid, M., Kasuya, H., \& Sakamoto, J. (2013). Knowledge, attitudes, and practices regarding HIV/AIDS among male high school students in Lao People's Democratic Republic. Journal of International AIDS Society, 16, 17. doi: 10.7448/IAS.16.1.17387

Tindall, N., \& Vardeman-Winter, J. (2011). Complications in segmenting campaign publics: Women of color explain their problems, involvement, and constraints in reading heart disease communication. Howard Journal of Communications, 22, 280-301. doi. 10.1080/10646175.2011.590407

United Nations. (2016). Sustainable goals to transform the world: 17 goals to transform our world. Retrieved from http://www.un.org/sustainabledevelopment/health/ United Nations International Children's Emergency Fund. (2013). Report on HIV/AIDS in Kenya. Retrieved from http://www.unicef.org/infobycountry/kenya_statistics.html\#116

United States Agency for International Development. (2005). Working report measuring HIV/AIDS stigma. Retrieved from http://www.icrw.org/files/publications/Working-Report-Measuring-HIV-StigmaResults-of-a-Field-Test-in-Tanzania.pdf

United States Agency for International Development. (2013). Kenya HIV/AIDS

Fact Sheet. Retrieved from https://www.usaid.gov/news-information/fact-sheets 
Van Buren, K. (2011). Music, HIV/AIDS and social change in Nairobi, Kenya. In G. Barz \& J. M. Cohen (Eds.), The culture of AIDS in Africa. Hope and healing through music and the arts (pp. 70- 84). New York, NY: Oxford University Press.

Weigel, F., Hazen, T., Cegielski, G., \& Hall, J. (2014). Diffusion of innovations and the theory of planned behavior in information systems research: A meta-analysis. Communications of the Association for Information Systems, 34, 619-936.

Retrieved from http://aisel.aisnet.org/cgi/viewcontent.cgi?article=3754\&context=cais Wilson, C. (2012). Critical analysis of HIV/AIDS communication messages (Master's thesis). Retrieved from UMI data base (Accession No. 1510761)

Yuh, J., Ellwanger, K., Potts, L., \& Ssenyonga, J. (2014). Stigma among HIV/AIDS patients in Africa: A critical review. Social and Behavioral Sciences, 140, 581585. doi: 10.1016/j.shspro.2014.04.474 


\section{APPENDIX A \\ RECRUITMENT E-MAIL}

Dear Participant,

I am a graduate student in the School of Communication, Illinois State University, conducting a research study on Beyond The Millennium Development Goals: An Evaluation of the War on HIV/AIDS in Kenya.

You are invited to participate in an online closed and open-ended questionnaire study regarding the progress made in the fight on HIV/AIDS in KENYA. Particularly, this study seeks to assess the achievements realized in fighting HIV/AIDS-related stigma, creating awareness, and preventing new infections. This study is very relevant in charting the way forward in the fight against the HIV/AIDS pandemic by revealing the gaps that need to be addressed in order to realize full success in this war.

The online questionnaire will take about 10-15 minutes. It will be anonymous (we will not track your IP address), and we will use no identifying names or comments in our study. Your participation will be completely voluntary. You may decide not to answer any question, and you can stop the interview at any time. To participate, you must be at least 18 years of age.

Please direct any questions and/or comments to Dr. John Baldwin, School of Communication, Illinois State University (jrbaldw@ilstu.edu) or Robert Nyaga, School of Communication, Illinois State University (rnyaga@ilstu.edu). 


\section{APPENDIX B}

\section{INFORMED CONSENT TO PARTICIPATE IN A RESEARCH STUDY}

\section{Dear Participant,}

I am a graduate student under the direction of Dr. John Baldwin in the School of

Communication. I am conducting a research study to examine the perceptions of Kenyans towards various aspects of HIV/AIDS in Kenya.

Your participation will involve completing an online, closed and open-ended questionnaire regarding the achievements realized in fighting HIV/AIDS-related stigma, creation of awareness, perception of media information and prevention of new infections. The survey should take about 10-15 minutes. To participate, you must be at least 18 years of age.

Your participation in this study is voluntary. If you choose not to participate or to withdraw from the study at any time, there will be no penalty, and neither will it affect your relationship with the researcher or Illinois State University. Your responses are anonymous. We will not track IP addresses, and any information that might allow someone to identify you will not be disclosed.

As a participant, you may feel emotional discomfort while discussing opinions and personal experiences regarding HIV/AIDS. You may feel uncomfortable discussing issues touching on a disease that may have infected someone close to you; however, we will not track IP addresses and you may stop the survey at any time. You will receive no 
compensation for this study. Researchers that study health communication will benefit from this study.

Please direct any questions and/or comments to Dr. John Baldwin (jrbaldw@ilstu.edu) or to me (rnyaga@ilstu.edu). If you have any questions about your rights as a subject/participant in this research, or if you feel you have been placed at risk, you can contact the Research Ethics \& Compliance Office at Illinois State University at (309) 438-2529. 


\section{APPENDIX C}

\section{SURVEY QUESTIONS}

\section{a). Demographic Information}

1. How do you identify yourself?

Male

Female

Transgendered

Prefer not to disclose

2. What is your age as per your last birthday?

3. What is your sexual orientation?

Heterosexual

Homosexual

Bisexual

Other

Prefer not to disclose

5. What is your marital status?

Married

Single

Divorced

In a domestic partnership

7. What is your country of residence (If not Kenya, for how many years have you lived in Kenya? 


\section{b). HIV Knowledge Questionnaire}

\section{Directions:}

In this scale HIV means human immunodeficiency virus and AIDS mean Acquired Immune Deficiency Syndrome. For each statement, please indicate "True” (T), "False” (F), or "I don't know" (DK). If you do not know, please do not guess; instead, please indicate "DK."

1. Coughing and sneezing DO NOT spread HIV.

T F DK

2. A person can get HIV by sharing a glass of water with someone who has HIV.

T $\quad \mathrm{F} \quad \mathrm{DK}$

3. Pulling out the penis before a man climaxes/cums keeps a woman from getting HIV during sex.

T F DK

4. A woman can get HIV if she has anal sex with a man.

T F DK

5. Showering, or washing one's genitals/private parts, after sex keeps a person from getting HIV

T $\quad \mathrm{F} \quad \mathrm{DK}$

6. All pregnant women infected with HIV will have babies born with AIDS.

T $\quad \mathrm{F} \quad \mathrm{DK}$

7. People who have been infected with HIV quickly show serious signs of being infected.

T F DK

8. There is a vaccine that can stop adults from getting HIV. $\quad$ T $\quad F \quad$ DK

9. People are likely to get HIV by deep kissing, putting their tongue in their partner's mouth, if their partner has HIV.

T F DK

10. A woman cannot get HIV if she has sex during her period. $\quad \begin{array}{lll}\mathrm{T} & \mathrm{F} & \mathrm{DK}\end{array}$

11. There is a female condom that can help decrease a woman's chance of getting HIV.

T $\quad \mathrm{F} \quad \mathrm{DK}$

12. A natural skin condom works better against HIV than does a latex condom.

T $\quad \mathrm{F} \quad \mathrm{DK}$

13. A person will NOT get HIV if she or he is taking antibiotics.

T $\quad \mathrm{F} \quad \mathrm{DK}$

14. Having sex with more than one partner can increase a person's chance of being infected with HIV.

T $\quad \mathrm{F} \quad \mathrm{DK}$

15. Taking a test for HIV one week after having sex will tell a person if she or he has HIV.

T $\quad \mathrm{F} \quad \mathrm{DK}$ 
16. A person can get HIV by sitting in a hot tub or a swimming pool with a person who has HIV.

$\begin{array}{ccc}\mathrm{T} & \mathrm{F} & \mathrm{DK} \\ \mathrm{T} & \mathrm{F} & \mathrm{DK}\end{array}$

17. A person can get HIV from oral sex.

18. Using Vaseline or baby oil with condoms lowers the chance of getting HIV.

$\mathrm{T} \quad \mathrm{F} \quad \mathrm{DK}$

\section{c). HIV/AIDS Intervention Scale}

Directions: On the scales below, please indicate the degree to which you believe the following statements. Numbers " 1 " and "6" indicate a very strong feeling. Numbers "2" and "6" indicate a strong feeling. Numbers "3" and "5" indicate a fairly week feeling. Number "4" indicates you are undecided or do not understand the adjective pairs themselves. There are no right or wrong answers. Only indicate one number per line.

$\begin{array}{llllllll}\text { Various HIV/AIDS Interventions } & 1 & 2 & 3 & 4 & 5 & 6\end{array}$

a. Promotion of male circumcision reduces the risk of HIV/AIDS infection

$\begin{array}{llllll}1 & 2 & 3 & 4 & 5 & 6\end{array}$

b. Involving community opinion leaders in HIV/AIDS campaigns increases effectiveness of HIV/AIDS campaigns

$\begin{array}{llllll}1 & 2 & 3 & 4 & 5 & 6\end{array}$

c. Promotion of education in society helps to control infection and spread of HIV/AIDS.

d. Promotion of condom usage is not effective in HIV/AIDS control.

$\begin{array}{llllll}1 & 2 & 3 & 4 & 5 & 6\end{array}$

e. Government allocation of more budgetary resources for fighting HIV/AIDS can prevent new infections and control the disease.

$\begin{array}{llllll}1 & 2 & 3 & 4 & 5 & 6\end{array}$

f. Laws and policies are effective in controlling HIV/AIDS.

$\begin{array}{llllll}1 & 2 & 3 & 4 & 5 & 6\end{array}$

g. Encouraging abstinence among unmarried people is an effective way of controlling HIV/AIDS in Kenya.

$\begin{array}{llllll}1 & 2 & 3 & 4 & 5 & 6\end{array}$

h. Promotion of faithfulness in partners in sexual relationships is not an effective method of controlling HIV/AIDS. 


\section{d). Attitudes Towards HIV/AIDS positive Patients}

\section{Directions:}

For each statement, please indicate “True” (T), “False” (F), or “I don’t know” (DK). If you do not know, please do not guess; instead, please circle "DK.” PLHA Stands for a Person Living with HIV/AIDS.

a) In a market of several vendors, would you buy food from a person living with HIV/AIDS (PLHA) or suspected of HIV/AIDS?

Yes

No

I don't know

b) In your household, would you share utensils with a person living with HIV/AIDS (HIV/AIDS) or a person suspected of having HIV/AIDS?

Yes

No

I don’t know

c) Would you buy fresh vegetables from a shopkeeper or vendor if you knew that this person has the AIDS virus

Yes

No

I don't know 
d) If a relative of yours is infected with HIV/AIDS, would you be willing to care for her/him in the household?

Yes

No

I don’t know

e) If you selected YES in No. 4 above, what help would you give him/her?

\begin{tabular}{|l|l|l|l|}
\hline & Yes & No & I Do Not Know \\
\hline Balanced diet & & & \\
\hline Treatment and drugs & & & \\
\hline Counseling & & & \\
\hline Compassion and support & & & \\
\hline
\end{tabular}

f) If a male teacher has the AIDS virus but is not sick, should he continue teaching at the school?

Yes

No

I don't know

g) If a female teacher has the AIDS virus but is not sick, should she continue teaching at the school?

Yes

No

I don't know 


\section{e). Sources of HIV/AIDS information}

1. How frequently do you rely on each of the following sources of HIV/AIDS information?

\begin{tabular}{|l|l|l|l|l|l|}
\hline & $\begin{array}{l}\text { Not at } \\
\text { all }\end{array}$ & Rarely & Sometime & Frequently & Always \\
\hline Newspapers & & & & & \\
\hline Television & & & & & \\
\hline Internet & & & & & \\
\hline Friends & & & & & \\
\hline $\begin{array}{l}\text { Government } \\
\text { offices }\end{array}$ & & & & & \\
\hline
\end{tabular}

2. How frequently do you share HIV/AIDS information with each of the following?

\begin{tabular}{|l|l|l|l|l|l|}
\hline & $\begin{array}{l}\text { Not at } \\
\text { all }\end{array}$ & Rarely & Sometime & Frequently & Always \\
\hline $\begin{array}{l}\text { Family } \\
\text { members }\end{array}$ & & & & & \\
\hline Friends & & & & & \\
\hline $\begin{array}{l}\text { Colleagues at } \\
\text { work }\end{array}$ & & & & & \\
\hline Acquaintances & & & & & \\
\hline $\begin{array}{l}\text { Family } \\
\text { members }\end{array}$ & & & & & \\
\hline
\end{tabular}


3. Entertainment education is the use of creative messages in health campaigns to entertain the target audience while at the same time promoting prosocial behavior. How credible do you perceive entertainment education messages in the mass media?

Not credible at all

Mildly credible

Neutral/I don’t know

Somewhat credible

Very credible

4. On a scale provided below, what effects does involving the following groups in the HIV/AIDS campaigns have in making them successful? A very negative effect $=1$; A mildly negative effect $=2 \quad$ I don't know $=3$; A mildly positive effect $=4$, A very positive effect $=5$

\begin{tabular}{|l|l|l|l|l|l|}
\hline & 1 & 2 & 3 & 4 & 5 \\
\hline Religious leaders & & & & & \\
\hline Politicians & & & & & \\
\hline Community elders & & & & & \\
\hline Traditional healers (medicine men) & & & & & \\
\hline
\end{tabular}

5. In your opinion, does the Kenyan government invest enough resources (Capital, equipment, and personnel) in the fight against HIV/AIDS? Please explain your answer. 
APPENDIX D

ABBREVIATIONS AND ACRONYMS

AIDS Acquired Immune Deficiency Syndrome

ARV Antiretroviral

ART Antiretroviral Therapy

DOI Diffusion of Innovations Theory

EE Entertainment Education

FGM Female Genital Mutilation

HIV Human Immunodeficiency Syndrome

MDGs Millennium Development Goals

NACC National Aids Control Council of Kenya

NASCOP National AIDS and Sexually Transmitted Infections Control Program

NGOs Nongovernmental Organizations

PEPFAR President's Emergency Plan for AIDS Relief

STI Sexually Transmitted Infections

UNAIDS Joint United Nations Program on HIV/AIDS

UNDP United Nations Development Program

UNICEF United Nations International Children's Emergency Fund

USAID United States Agency for International Development 